\title{
Development of waterborne polyurethane-ureas added with plant extracts: Study of different incorporation routes and their influence on particle size, thermal, mechanical and antibacterial properties
}

\author{
Arantzazu Santamaria-Echart ${ }^{\mathrm{a}}$, Isabel Fernandes ${ }^{\mathrm{b}}$, Filomena Barreiro ${ }^{\mathrm{b}}$, Aloña Retegi ${ }^{\mathrm{a}}$, \\ Aitor Arbelaiz ${ }^{\mathrm{a}}$, Maria Angeles Corcuera ${ }^{\mathrm{a}, *}$, Arantxa Eceiza ${ }^{\mathrm{a}, *}$ \\ a Group 'Materials + Technologies', Department of Chemical and Environmental Engineering, Faculty of Engineering, University of the Basque Country, Pza Europa 1, \\ 20018 Donostia-San Sebastián, Gipuzkoa, Spain \\ ${ }^{\mathbf{b}}$ Laboratory of Separation and Reaction Engineering - Laboratory of Catalysis and Materials (LSRE-LCM), Polytechnic Institute of Bragança, Campus of Santa Apolonia, \\ 5300-253 Bragança, Portugal
}

\section{A R T I C L E I N F O}

\section{Keywords:}

Waterborne polyurethane-urea

Plant extracts

Incorporation route

Salvia officinalis

Melissa officinalis

Antibacterial properties

\begin{abstract}
A B S T R A C T
Polyurethane-ureas are a versatile family of polymers which can be employed in a wide range of applications. Among them, waterborne polyurethane-urea (WBPUU) dispersions are gaining relevance in the field of environmentally-friendly products since their productive process adopts green synthesis routes, avoiding the use of organic solvents. Furthermore, their waterborne character can be exploited to incorporate several water compatible ingredients able to confer functional properties to the final materials. Among them, plant extracts, which are known to have relevant bioactivities, can be viewed as interesting candidates. Therefore, in this work, two extracts known to present antimicrobial activity (Melissa officinalis L. and Salvia officinalis L.) were obtained by the infusion method and incorporated into the WBPUU (1, 3 and $5 \mathrm{wt} \%$ ) following different incorporation routes comprising its adding during different phases of the productive process (post-, in-situ and pre- methods). Thereafter films were prepared by solvent-casting and characterized from the viewpoint of physicochemical, thermal, mechanical, thermomechanical and antibacterial properties and morphologically. The studied incorporation routes resulted in different intercalation mechanisms that varied from extract positioned among the polyurethane-urea nanoparticles (post-method) to extract partially embedded inside them (in-situ and premethods), which produced stiffening or flexibilizing effects in the produced films, enhancing in general the antimicrobial characteristics of films after 4 days of incubation comparing with base WBPUU, especially when the extract is embedded.
\end{abstract}

\section{Introduction}

In the versatile family of polyurethane-ureas, the use of waterborne polyurethane-urea (WBPUU) dispersions is gaining importance due to the environmentally-friendly character of their synthesis process, reducing, or even eliminate, the use of volatile organic compounds [1]. In this way, low viscosity and high solids content dispersions presenting no flammability are obtained [2]. The incorporation of an internal emulsifier along the polyurethane-urea backbone provides the required hydrophilicity [3], which following an adequate composition ensures stable dispersions for months. From these dispersions, WBPUU films presenting suitable properties such as impact resistance, solvent resistance and adhesion to different substrates can be achieved [4].
Furthermore, WBPUU find a broad range of applications such as paintings, inks, adhesives, coatings and medical uses [5-10].

The waterborne character of these systems enables an easy use of water soluble additives. Among them, the use of vegetal renewable sources to obtain natural additives, through extraction with water (a green solvent), is an interesting approach reinforced by the extensively documented bioactivity of such extracts. In fact, plants are rich sources of bioactive compounds, namely alkaloids, flavonoids, tannins and phenolic compounds. The composition of the obtained extracts vary depending on the plant, growing conditions and used extraction process [11-13], conferring bioactive properties, and among them antibacterial activity.

Examples include Salvia officinalis L. (Lamiaceae family), commonly

\footnotetext{
* Corresponding authors.

E-mail addresses: arantzazu.santamaria@ehu.eus (A. Santamaria-Echart), ipmf@ipb.pt (I. Fernandes), barreiro@ipb.pt (F. Barreiro), alona.retegui@ehu.eus (A. Retegi), aitor.arbelaiz@ehu.eus (A. Arbelaiz), marian.corcuera@ehu.eus (M.A. Corcuera), arantxa.eceiza@ehu.eus (A. Eceiza).
} 
known as sage and traditionally used in culinary and medicinal preparations [14], whose chemical composition is associated with effective antibacterial, antioxidant and anti-inflammatory properties [14,15]. Salvia officinalis is characterized by presenting mainly terpenoids (such as $\alpha$ - and $\beta$-thujone, camphor and 1,8-cineole), and a polyphenolic fraction which includes phenolic acids (rosmarinic, ferulic and caffeic acid), flavonoids (luteolin, apigenin and naringenin) and diterpenes (carnosic acid, carnosol, rosmanol, epirosmanol and isorosmanol) $[16,17]$. In this way, preparations based on Salvia officinalis can be employed in different forms (liquid extracts, essential oils or powder forms) attending to their final application [18]. For example, Bakota and co-workers [19], obtained from this vegetal material an extract rich in polyphenols, demonstrating its antioxidant effect, and suitability to be used in different fields, such as the one of food industry.

Also, Melissa officinalis L. (Lamiaceae family) known as Lemon balm due to its flavor and fragrance and traditionally used to treat headache, migraine and nervous tension, is recognized by its antibacterial, antiinflammatory and antioxidant properties [11,20,21]. Melissa officinalis is constituted mainly by eugenol, tannins, flavonoids such as luteolin, apigenin 7-O-beta-D-glucopyranoside, terpenes (sesquiterpenes, triterpenes and monoterpene glycosides), hydroxycinnamic acid derivatives, specifically rosmarinic acid, caffeic acid, chlorogenic acid, and metrilic acid [22-24]. Attending to their composition Melissa officinalis extracts can be employed in a wide range of applications. For example, Echem and Chukwuike [22] demonstrated the availability of Melissa officinalis extracts for inhibiting the corrosion of aluminium in hydrochloric acid medium. In another work Cunha et al. [25] analyzed the efficacy of these extracts against Leishmania and Trypanosoma activity, focusing on biomedical applications.

Therefore, in this work a base WBPUU dispersion was synthesized and incorporated with aqueous extracts of Salvia officinalis L. and Melissa officinalis L. having in view the obtainment of products with improved antimicrobial activity. Three incorporation pathways were designed, where the extracts were added at three different contents ( 1 , 3 and $5 \mathrm{wt} \%$ ). The incorporation routes were defined taking into account key points of the productive process. In brief, extracts were always added dissolved in water as follows: (i) in the first route, postmethod, the extract was added once WBPUU dispersion was synthesized, thus after the formation of the WBPUU particles; (ii) in the second via, in-situ method, the extract was gradually added during the phase inversion step, i.e. simultaneously with the WBPUU nanoparticles formation; (iii) in the third alternative, pre-method, the extract was added in the beginning of the phase inversion step, i.e. before nanoparticles formation. The obtained dispersions were characterized in terms of $\mathrm{pH}$, viscosity and particle size, and the prepared films analyzed in what concerns morphology and physicochemical, thermal, mechanical and thermomechanical properties. Moreover, antibacterial properties of the films were analyzed against Gram positive Staphylococcus aureus ( $S$. aureus), and Gram negative Escherichia coli (E. coli) and Pseudomonas aeruginosa ( $P$. aeruginosa) which are microorganisms responsible for many infections and common pathogens with difficult treatment [26].

\section{Experimental}

\subsection{Materials}

WBPUU dispersions were synthesized using poly( $\varepsilon$-caprolactone) diol (PCL) $\left(\bar{M}_{w}=2000 \mathrm{~g} \mathrm{~mol}^{-1}\right)$ provided by Solvay as soft segment. Isophorone diisocyanate (IPDI), purchased from Bayer and ethylenediamine (EDA) supplied by Panreac were used as the isocyanate and as the chain extender components, respectively. 2,2-Bis(hydroxymethyl) propionic acid (DMPA), purchased from Fluka, was selected as the internal emulsifier. Triethylamine (TEA), provided by Fluka, was used to neutralize the ionic groups of DMPA. PCL and DMPA were dried under vacuum at $50{ }^{\circ} \mathrm{C}$ during $4 \mathrm{~h}$ previously to the synthesis process. Dry acetone, purchased from Panreac was employed as viscosity modulator, and dibutyltin dilaurate (DBTDL), supplied by Fluka, was used as catalyst.

Salvia officinalis L. from Raizes da Natureza and Melissa officinalis L. from Tetley were acquired in a local herbalist.

\subsection{Obtainment of Salvia and Melissa extracts}

Extracts of Salvia officinalis L. and Melissa officinalis L. were obtained by the infusion method from dry plant material according to the procedure described in the work of Isabel C.F.R. Ferreira and co-workers [14]. The extracts were selected due to their recognized antimicrobial activity, as described in literature [11,14,20]. Briefly, $20 \mathrm{~g}$ of grinding plant was added to $800 \mathrm{~mL}$ of boiling distilled water and maintained for $5 \mathrm{~min}$. Then, the resultant suspension was filtered and lyophilized to obtain the extract in powder form. For each plant, the extraction yield was calculated according to Eq. (1):

yield $(\%)=\frac{W_{i}-W_{f}}{W_{i}} \cdot 100$

Where $\mathrm{W}_{i}$ refers to the used plant weight and $\mathrm{W}_{f}$ to the obtained extract weight. Yields of $13 \pm 1 \%$ and $17 \pm 2 \%$ were obtained for Salvia and Melissa extracts, respectively.

\subsection{Synthesis of waterborne polyurethane-urea}

Waterborne polyurethane-urea dispersions were synthesized following a two-step polymerization process using a NCO/OH ratio of 1.67 and $5 \mathrm{wt} \%$ of DMPA in the prepolymer synthesis step, resulting in a hard segment (HS) content around $32 \mathrm{wt} \%$. The reaction was carried out in a $500 \mathrm{~mL}$ four neck jacketed reactor equipped with an intracooler, a thermocouple and a mechanical stirrer and controlled from a computer during the synthesis process.

The synthesis was carried out under nitrogen atmosphere and the reaction progress followed by the dibutylamine back titration method, according to ASTM D 2572-97. PCL, IPDI and DBTDL (0.037 wt\%) were mixed in the reactor and allowed to react at $80^{\circ} \mathrm{C}$ until the theoretical NCO value was reached. Afterwards, the mixture was cooled to $50^{\circ} \mathrm{C}$ and the previously neutralized DMPA (with TEA), dissolved in a small amount of acetone, incorporated. The final NCO terminated prepolymer was cooled to $25^{\circ} \mathrm{C}$ and distilled water was added dropwise under vigorous stirring. The obtained dispersion was heated to $35^{\circ} \mathrm{C}$ previously to chain extension with EDA. For that EDA added dissolved in $20 \mathrm{~mL}$ of distilled water at a flow rate of $0.3 \mathrm{~mL} \mathrm{~min}^{-1}$. The needed amount of EDA was calculated based on a chain extension degree of $40 \%$. Finally, acetone was removed in a rotary evaporator at $40{ }^{\circ} \mathrm{C}$ and 350 mbar, thus obtaining a dispersion with a solids content of around $35-40 \mathrm{wt} \%$.

\subsection{Salvia- and Melissa-based WBPUU dispersions and films preparation}

Extracts were incorporate at contents of 1, 3 and 5\% (wt, prepolymer-basis). Three alternative incorporation routes were designed for the preparation of the Salvia- and Melissa-based WBPUU:

Post-method: in this method, the required amount of extract was dissolved in distilled water and incorporated dropwise to the synthesized WBPUU under mechanical stirring. This procedure was done previously to the corresponding film preparation. For that $10 \mathrm{~mL}$ of dispersion were mixed with $10 \mathrm{~mL}$ of the extract solution using the required amount of extract.

In-situ method: according to this method the extract was dissolved in the distilled water used in the phase inversion step. In this way, the extract was incorporated progressively during the phase inversion step, i.e. during the WBPUU nanoparticles formation.

Pre-method: in this method, the extract was dissolved in a small amount of distilled water $(15 \mathrm{~mL})$ and incorporated, in one portion, to 


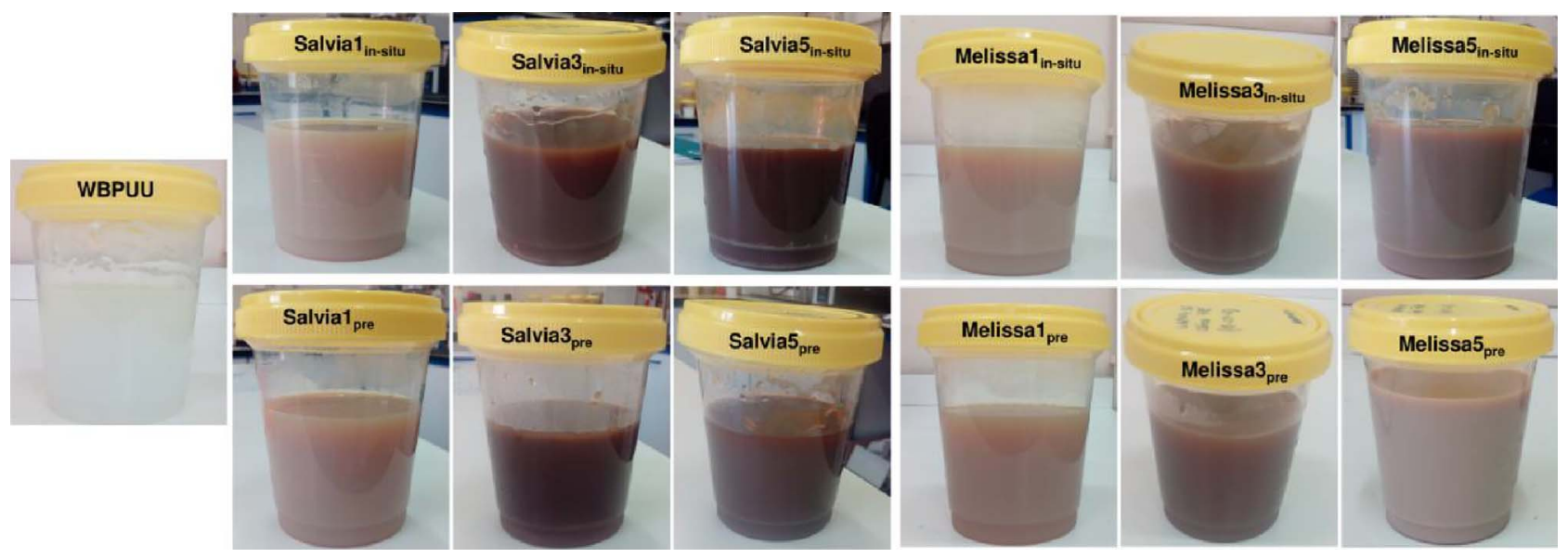

Fig. 1. Image of synthesized base WBPUU and WBPUU containing bioactive Salvia and Melissa extracts dispersions.

Table 1

$\mathrm{pH}$, viscosity and solids content values of base WBPUU and WBPUU containing Salvia and Melissa extracts bioactive dispersions.

\begin{tabular}{|c|c|c|c|c|c|c|}
\hline \multirow[t]{2}{*}{ Sample } & \multicolumn{3}{|c|}{ Salvia-based WBPUU dispersions } & \multicolumn{3}{|c|}{ Melissa-based WBPUU dispersions } \\
\hline & $\mathrm{pH}$ & Viscosity (mPa s) & Solids content (\%) & $\mathrm{pH}$ & Viscosity (mPa s) & Solids content $(\%)$ \\
\hline WBPUU & 7.29 & $23.4 \pm 0.1$ & $37.4 \pm 0.0$ & 7.29 & $23.4 \pm 0.1$ & $37.4 \pm 0.0$ \\
\hline $1_{\text {post }}$ & 8.22 & - & - & 7.85 & - & - \\
\hline 3 post & 8.14 & - & - & 7.51 & - & - \\
\hline 5 post & 7.76 & - & - & 7.42 & - & - \\
\hline $\mathbf{1}_{\text {in-situ }}$ & 7.63 & $21.4 \pm 0.2$ & $37.1 \pm 0.1$ & 7.67 & $21.5 \pm 0.3$ & $37.5 \pm 0.2$ \\
\hline 3 in-situ & 7.66 & $49.7 \pm 0.6$ & $35.2 \pm 0.1$ & 8.50 & $1797.0 \pm 1.2$ & $31.8 \pm 0.5$ \\
\hline 5 in-situ & 7.67 & $216.2 \pm 0.6$ & $35.5 \pm 0.0$ & 7.44 & $88.9 \pm 0.2$ & $33.1 \pm 0.2$ \\
\hline $\mathbf{1}_{\text {pre }}$ & 7.53 & $22.6 \pm 0.3$ & $37.5 \pm 0.2$ & 7.50 & $19.2 \pm 0.3$ & $37.1 \pm 0.1$ \\
\hline 3 pre & 7.57 & $79.7 \pm 0.6$ & $34.5 \pm 0.0$ & 7.51 & $22.1 \pm 0.4$ & $34.0 \pm 0.0$ \\
\hline 5 pre & 7.63 & $69.3 \pm 0.6$ & $36.6 \pm 0.2$ & 7.25 & $9.4 \pm 0.2$ & $30.2 \pm 0.4$ \\
\hline
\end{tabular}

the reactor just before water addition to initialize the phase inversion step, i.e. previously to the WBPUU nanoparticles formation.

Films of Salvia- and Melissa-based WBPUU were prepared by the solvent-casting method. Briefly, the needed volume of dispersion (around $20 \mathrm{~mL}$ ) was poured into a Teflon mold and allowed to dry at room conditions during 1 week. Finally, films were dried at $60^{\circ} \mathrm{C}$ at 800 mbar for 1 day. The resultant films were stored in a desiccator before characterization. Waterborne polyurethane-urea samples were coded as SalviaX $\mathrm{y}_{\mathrm{y}}$ or MelissaX $\mathrm{y}$, where " $\mathrm{X}$ " referred to Salvia or Melissa weight content in the polyurethane-urea and " $\mathrm{y}$ " specifies extract incorporation route "post", "in-situ" or "pre" Furthermore, base polyurethane-urea was coded as WBPUU.

\subsection{Characterization}

\subsubsection{Dispersions characterization}

Dispersions were characterized in what concerns $\mathrm{pH}$, viscosity, particle size and solids content. The $\mathrm{pH}$ was measured using a $\mathrm{pH}$ meter GLP22 of Crison, calibrated with $\mathrm{pH} 4.00$ and 7.00 buffer solutions standards. Viscosity measurements were carried out using a Visco Star Fungilab of concentric cylinders rotational viscosimeter. The viscosity $(\eta)$ values were determined by averaging 3 measurements using $8 \mathrm{~mL}$ of dispersion at $25^{\circ} \mathrm{C}$. Particle size and distribution of base WBPUU and WBPUU dispersions containing plant extracts were analyzed using a Mastersizer 3000 Hydro particle size analyzer of Marlvern. Samples were analyzed at $25^{\circ} \mathrm{C}$ by averaging 5 measurements of the diluted dispersions. Finally, solids content of base WBPUU and WBPUU dispersions containing plant extracts was calculated gravimetrically determining the relation between the weight of the polyurethane-urea in dry and in dispersion state. With this purpose, for each sample, around $1 \mathrm{~g}$ of dispersion was weighted before and after being dried in an oven at $105^{\circ} \mathrm{C}$ for $1 \mathrm{~h}$, by triplicate.

\subsubsection{Films characterization}

Colorimetry tests were carried out using a Konika Minolta sphereintegrated spectrophotometer (CM-2600d) in order to determine the reflectance factor $\rho(\lambda)$ of films in the range of $370-740 \mathrm{~nm}$ with the D65 illuminant and the CIE-1964 standard observer.

Fourier transform infrared spectroscopy (FTIR) was used to identify characteristic functional groups and hydrogen bonding interactions in the produced films. Spectra were recorded using a Nicolet Nexus spectrometer provided with a MKII Golden Gate accessory (Specac) with diamond crystal at a nominal incidence angle of $45^{\circ}$ and ZnSe lens. Spectra were collected at a spectral resolution of $8 \mathrm{~cm}^{-1}$ by accumulating 64 scans in the range between 4000 and $650 \mathrm{~cm}^{-1}$.

Thermal behavior was analyzed by differential scanning calorimetry (DSC) using a DSC 204 F1 Phoenix equipment of Netzsch. 5-10 mg of sample film were sealed in aluminium pans, and subjected to a heating scan from -75 to $200{ }^{\circ} \mathrm{C}$ at a heating rate of $10^{\circ} \mathrm{C} \mathrm{min}^{-1}$. Glass transition temperature $\left(\mathrm{T}_{\mathrm{g}}\right)$ was referred to the inflection point of the heat capacity change whereas the maximum of endothermic peak was settled as the melting temperature $\left(\mathrm{T}_{\mathrm{m}}\right)$ being the area under the peak the melting enthalpy $\left(\Delta \mathrm{H}_{\mathrm{m}}\right)$.

Mechanical behavior was determined using a MTS Insight 10 testing machine provided with a $250 \mathrm{~N}$ load cell and pneumatic grips to hold samples. Five specimens ( $8 \mathrm{~mm}$ in length, $2.5 \mathrm{~mm}$ in width and $0.4 \mathrm{~mm}$ in thickness) were averaged for each system at room temperature. Films tensile modulus (E), yield stress $\left(\sigma_{\mathrm{y}}\right)$, stress at break $\left(\sigma_{\mathrm{b}}\right)$ and strain at break $\left(\varepsilon_{\mathrm{b}}\right)$ were determined from stress-strain curves obtained at a crosshead speed of $50 \mathrm{~mm} \mathrm{~min}^{-1}$.

The themomechanical behavior was analyzed by dynamic mechanical analysis (DMA) using an Eplexor $100 \mathrm{~N}$ analyser Gabo 

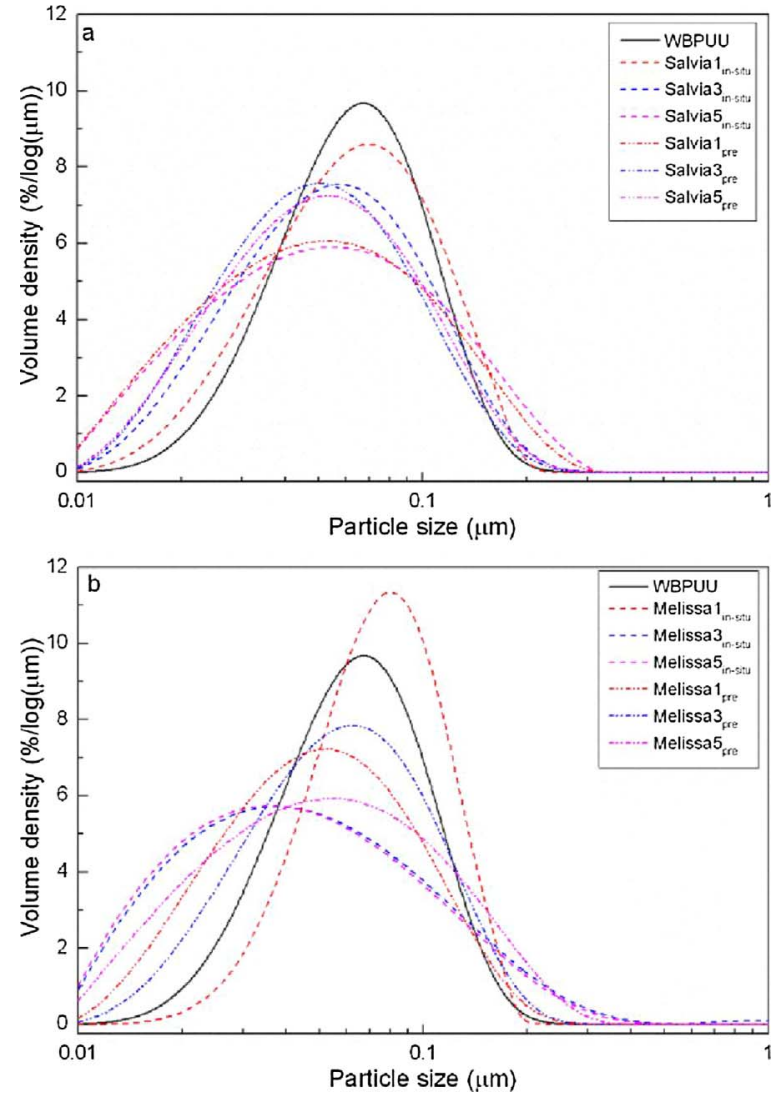

Fig. 2. Particle size distributions of base WBPUU and WBPUU containing a) Salvia and b) Melissa extracts bioactive dispersions prepared by in-situ and pre-methods.

Table 2

Particle sizes of base WBPUU and WBPUU containing Salvia and Melissa extracts bioactive dispersions to 10,50 and $90 \%$ of the number of nanoparticles measured in the samples. The deviation in all samples was lower than $10^{-3}$.

\begin{tabular}{|c|c|c|c|c|c|c|}
\hline \multirow[t]{2}{*}{ Sample } & \multicolumn{3}{|c|}{$\begin{array}{l}\text { Salvia-based WBPUU dispersions } \\
\text { particle size }(\mathrm{nm})\end{array}$} & \multicolumn{3}{|c|}{$\begin{array}{l}\text { Melissa-based WBPUU dispersions } \\
\text { particle size }(\mathrm{nm})\end{array}$} \\
\hline & $\mathrm{D}_{10}$ & $\mathrm{D}_{50}$ & $\mathrm{D}_{90}$ & $\mathrm{D}_{10}$ & $\mathrm{D}_{50}$ & $\mathrm{D}_{90}$ \\
\hline WBPUU & 34.7 & 69.0 & 135 & 34.7 & 69.0 & 135 \\
\hline $\mathbf{1}_{\text {in-situ }}$ & 30.1 & 67.0 & 130 & 42.7 & 79.6 & 133 \\
\hline $3_{\text {in-situ }}$ & 24.9 & 58.4 & 131 & 17.4 & 46.6 & 148 \\
\hline $5_{\text {in-situ }}$ & 19.6 & 55.0 & 148 & 17.1 & 45.1 & 143 \\
\hline $1_{\text {pre }}$ & 19.3 & 52.7 & 138 & 22.7 & 54.0 & 127 \\
\hline $3_{\text {pre }}$ & 23.0 & 52.4 & 119 & 27.0 & 62.3 & 135 \\
\hline $5_{\text {pre }}$ & 22.9 & 54.5 & 127 & 19.6 & 54.6 & 147 \\
\hline
\end{tabular}

equipment. Tensile mode measurements were carried out from -100 to $100{ }^{\circ} \mathrm{C}$ at a heating rate of $2{ }^{\circ} \mathrm{C} \mathrm{min}{ }^{-1}$. The static strain was established as $0.05 \%$ and the operating frequency was fixed at $1 \mathrm{~Hz}$.

The morphology of the base WBPUU and the WBPUU containing $3 \mathrm{wt} \%$ of Salvia and Melissa extracts was determined by atomic force microscopy (AFM) using a Nanoscope IIIa scanning probe microscope (Multimode TM Digital instruments) with an integrated force generated by cantilever/silicon probes, applying a resonance frequency of about $180 \mathrm{kHz}$. The images were obtained at room temperature in tapping mode using a cantilever with a tip radius of $5-10 \mathrm{~nm}$ and was $125 \mu \mathrm{m}$ long. Samples were prepared by spin-coating (Spincoater P6700) a droplet of the dispersions on glass supports at $1200 \mathrm{rpm}$ for $130 \mathrm{~s}$.

The antibacterial assays were performed using Gram positive bacteria Staphylococcus aureus ATCC 19213 and Gram negative bacteria Escherichia coli ATCC 10536 and Pseudomonas aeruginosa ATCC 9027 as test microorganisms. The method was based on the Kirby-Bauer modified test [27]. Briefly, the bacteria inoculums were prepared by aseptically transferring 4 isolated colonies of each one, to separate test tubes containing nutrient broth, which were then incubated for 1 day at $37^{\circ} \mathrm{C}$. The inoculums were diluted to $0.5 \mathrm{McF}$ arland turbidity standard (corresponding to a concentration of $1.5-3.0 \times 10^{8} \mathrm{CFU} / \mathrm{mL}$ ) using sterilized Ringer solution. The concentration of the bacteria dilutions was also controlled by UV-vis spectrophotometry by measuring the absorbance at $625 \mathrm{~nm}$. Then, the bacteria solutions were inoculated in Mueller Hinton Agar plates, using a sterilized swab. The inoculated plates were left to dry for a short period of time. After that, a piece of sample with $1.5 \mathrm{~cm}$ of diameter of the base and waterborne polyurethane-urea films containing plant extracts was placed in the center of the plate. The plates were incubated at $37^{\circ} \mathrm{C}$ for $24 \mathrm{~h}$. After this period, the plates were analyzed to measure the diameter of the inhibition zone and the growth of the bacteria on both film's surface and bottom. Then, the incubation was further maintained during 4 days in order to evaluate the growth evolution of the inhibition zone derived from the extract diffusion, and the bacteria biofilm formation on the film's surface.

\section{Results and discussion}

\subsection{Dispersions characterization}

The base WBPUU (WBPUU without added extract), as well as the Salvia- and Melissa-based WBPUU prepared using the in-situ and premethod (i.e. the dispersions prepared with extract addition during the synthesis process) are shown in Fig. 1. The base WBPUU dispersion presented a white and translucent appearance. Instead, the Salvia- and Melissa-based WBPUU dispersions, presented a browner-like aspect, fact attributed to the extract color itself, and increased darkness as the extract content increased. Furthermore, Melissa-based dispersions were lighter when compared with their homologous prepared with Salvia.

Regarding WBPUU dispersions characterization, $\mathrm{pH}$, viscosity and solids content values are shown in Table 1. For Salvia- and Melissabased solutions $\mathrm{pH}$ values of 5.52 and 5.67 were obtained (data not shown in the Table), fact attributed to the presence, in the extract, of phenolics and flavonoids, compounds which might presented acidic groups [14]. For the base WBPUU dispersion, a value of 7.29 was measured, which resulted in the typical range founded in literature, corroborating that carboxylic groups were successfully neutralized $[28,29]$.

Analyzing the $\mathrm{pH}$ values of Salvia- and Melissa-based dispersions, fluctuations in $\mathrm{pH}$ were observed as a function of the used extract content, as well as, of the incorporation route. In the case of the postmethod, and comparing with the base WBPUU, higher $\mathrm{pH}$ values were obtained, but decreasing as the extract content increases. However, when the in-situ and pre-method incorporation routes were used, i.e. when Salvia and Melissa extracts were added during the synthesis process, extract compounds might became entrapped in the nanoparticles, thus less significant variations were observed. This fact can be related with the greater mobility, or freedom, of the extract compounds incorporated by the post-method, resulting in improved interaction ability where the ionic character would displace the $\mathrm{pH}$ equilibrium.

Analyzing the viscosity values, showed in Table 1, it was observed that, in general, extract content increase led to dispersion viscosity increase, fact that can be associated with modifications in the surface shear stress and interactions in the system [30]. Nevertheless, at the lowest Salvia and Melissa contents (1 $\mathrm{wt} \%$ ), viscosity values inferior to the ones of base WBPUU dispersion were obtained. This fact can be related with the presence of hydrophilic groups (e.g. hydroxyls in the phenolic compounds), favoring the dispersion formation and stability of the formed polyurethane-urea particles, where they can act as a surfactant [31]. In turn, when the extract content increased, this effect was relieved by hindrance and intensification of interactions, resulting in a viscosity growth. Also, considering the effectiveness of the extract to 


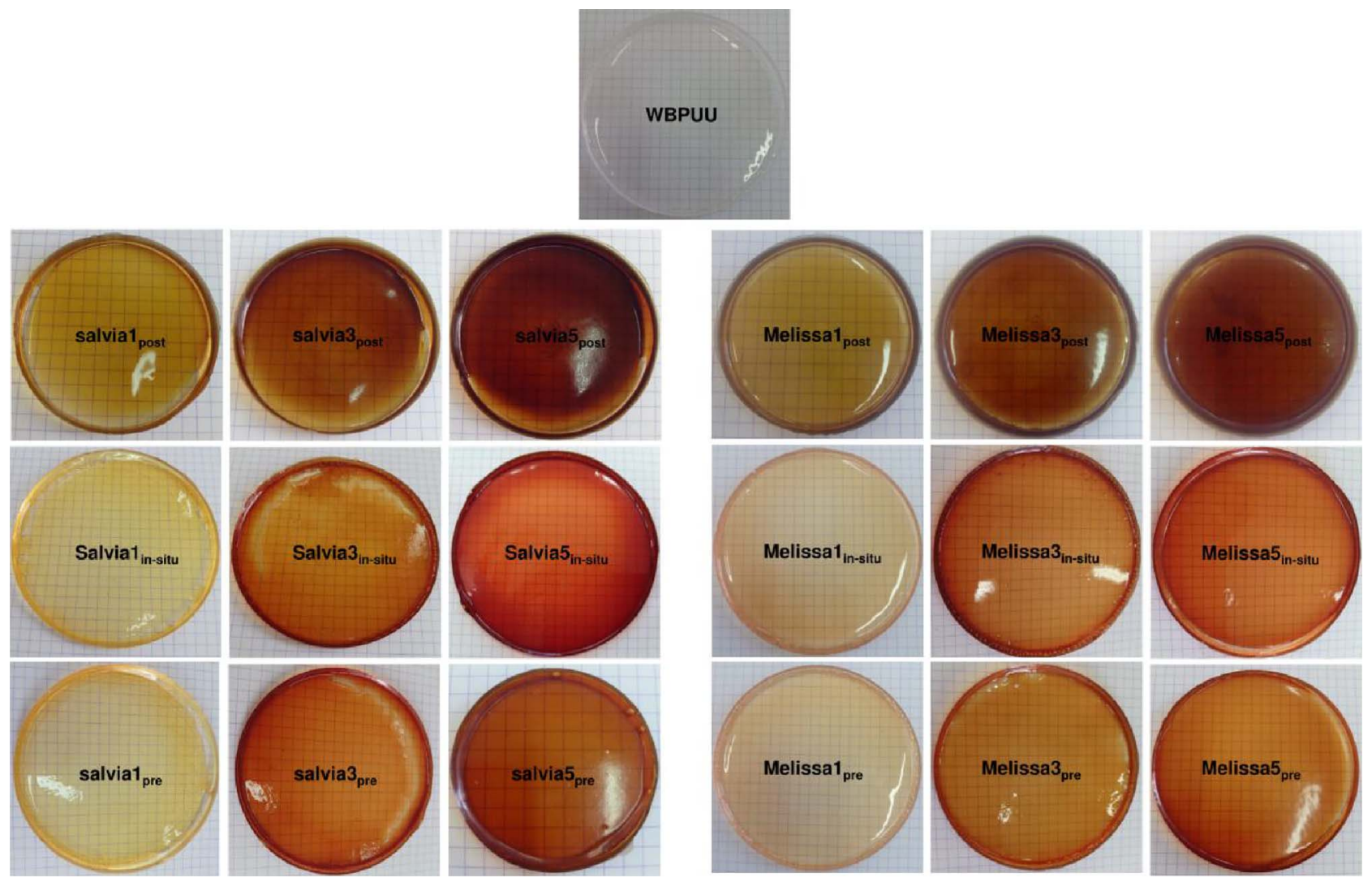

Fig. 3. Image of base WBPUU and WBPUU bioactive films containing Salvia and Melissa extracts prepared by solvent-casting.

Table 3

Colorimetric $\mathrm{L}^{*}, \mathrm{a}^{*}, \mathrm{~b}^{*}$ and $\Delta \mathrm{E}_{\text {post-sample }}$ (color difference respect to post-method samples) values of base WBPUU and WBPUU containing Salvia and Melissa extracts.

\begin{tabular}{|c|c|c|c|c|}
\hline Sample & $\mathrm{L}^{*}$ & $a^{*}$ & $b^{*}$ & $\Delta \mathrm{E}_{\text {post-sample }}$ \\
\hline WBPUU & $44.72 \pm 0.29$ & $-1.01 \pm 0.05$ & $-4.44 \pm 0.12$ & - \\
\hline Salvia1 $_{\text {post }}$ & $33.03 \pm 0.83$ & $2.48 \pm 0.21$ & $12.98 \pm 1.00$ & - \\
\hline Salvia $3_{\text {post }}$ & $26.44 \pm 0.04$ & $5.26 \pm 0.11$ & $6.00 \pm 0.42$ & - \\
\hline Salvia5 & $24.93 \pm 0.06$ & $4.45 \pm 0.05$ & $3.25 \pm 0.19$ & - \\
\hline Salvia1 $_{\text {in-situ }}$ & $43.59 \pm 0.22$ & $-3.51 \pm 0.10$ & $11.21 \pm 0.38$ & 12.27 \\
\hline Salvia $_{\text {in-situ }}$ & $33.52 \pm 0.24$ & $7.30 \pm 0.15$ & $14.68 \pm 0.22$ & 11.39 \\
\hline Salvia5 $_{\text {in-situ }}$ & $28.24 \pm 0.14$ & $5.09 \pm 0.07$ & $8.06 \pm 0.25$ & 5.87 \\
\hline Salvia $_{\text {pre }}$ & $43.16 \pm 0.18$ & $-3.08 \pm 0.06$ & $10.10 \pm 0.08$ & 11.91 \\
\hline Salvia3 $3_{\text {pre }}$ & $34.82 \pm 0.05$ & $5.45 \pm 0.06$ & $15.92 \pm 0.13$ & 12.99 \\
\hline Salvia5 & $28.29 \pm 0.15$ & $4.04 \pm 0.03$ & $8.29 \pm 0.06$ & 6.07 \\
\hline Melissa $_{\text {post }}$ & $32.92 \pm 0.21$ & $2.34 \pm 0.06$ & $12.43 \pm 0.29$ & - \\
\hline Melissa $_{\text {post }}$ & $26.70 \pm 0.19$ & $4.60 \pm 0.10$ & $6.27 \pm 0.14$ & - \\
\hline Melissa5 & $25.33 \pm 0.03$ & $5.24 \pm 0.44$ & $4,38 \pm 0.11$ & - \\
\hline Melissa $_{\text {in-situ }}$ & $40.79 \pm 0.08$ & $-1.33 \pm 0.05$ & $10.53 \pm 0.09$ & 8.89 \\
\hline Melissa $_{\text {in-situ }}$ & $35.71 \pm 0.07$ & $4.12 \pm 0.11$ & $15.89 \pm 0.17$ & 13.19 \\
\hline Melissa5 $_{\text {in-situ }}$ & $31.43 \pm 0.09$ & $3.09 \pm 0.11$ & $10.78 \pm 0.13$ & 9.10 \\
\hline Melissa $_{\text {pre }}$ & $42.22 \pm 0.09$ & $-1.76 \pm 0.05$ & $11.27 \pm 0.10$ & 10.23 \\
\hline Melissa3 $_{\text {pre }}$ & $35.31 \pm 0.03$ & $3.74 \pm 0.07$ & $14.86 \pm 0.14$ & 12.19 \\
\hline Melissa5 $_{\text {pre }}$ & $30.45 \pm 0.02$ & $5.66 \pm 0.13$ & $10.40 \pm 0.07$ & 7.91 \\
\hline
\end{tabular}

favor the dispersion formation, which leads to slightly smaller nanoparticles, as will be shown later, but more numerous, the effect on viscosity increase is also expected [32]. Furthermore, although viscosity of bioactive dispersions prepared by post-method are not shown in Table 1, it is worth noting that the addition of the extract dissolved in additional distilled water caused a dilution effect in the system, leading to lower viscosity values.

The particle size distribution of the base WBPUU and the Salvia- and Melissa-based WBPUU dispersions prepared by in-situ and by the premethods, and containing 1, 3 and $5 \mathrm{wt} \%$ of extract, were measured by particle size analyzer and results are shown in Fig. 2.
Additionally, Table 2 presents the corresponding values for $\mathrm{D}_{10}, \mathrm{D}_{50}$ and $\mathrm{D}_{90}$, which represent the size below which 10,50 and $90 \%$ of the nanoparticles, in volume, exist. It was observed, in general, and comparing with the base WBPUU, that the particle size distribution broadens to smaller particle sizes as a consequence of extract incorporation, both for Salvia and Melissa extracts. This fact corroborates the nature of some extract compounds, whose character and chemical structure can promote their activity as natural surfactants [33-35], favoring the dispersion formation and thus contributing to the achievement of smaller particles. Furthermore, some differences were observed depending on the employed incorporation method. In the case of the in-situ method a reduction in $\mathrm{D}_{10}$ and $\mathrm{D}_{50}$ values was noticed, which became more noticeable as the extract content increases. In the pre-method, a reduction in the particle size was also observed, but remained almost unchangeable with the increase of extract content. Thereby, the chosen extract incorporation route influenced the dispersion formation. In the case of the in-situ method, since the extract was incorporated progressively along the entire course of the inversion phase, the effect was more perceptible as the extract content increases. In turn, in the pre-method, taking into account that the total amount of extract was incorporated prior to the phase inversion occurrence, it will be intercalated between polyurethane chains, causing a more discernible effect at low extract contents, and therefore, despite increasing the extract content, only a slightly variation was observed.

\subsection{Films characterization}

Films prepared from the base WBPUU and the Salvia- and Melissabased WBPUU dispersions, using the solvent-casting method, are shown in Fig. 3. Analyzing the images visually, it can be noticed that the base WBPUU dispersion resulted in bright and transparent films. The addition of extract rendered the films browner, being the effect more significant as the extract content increased, but maintaining the 


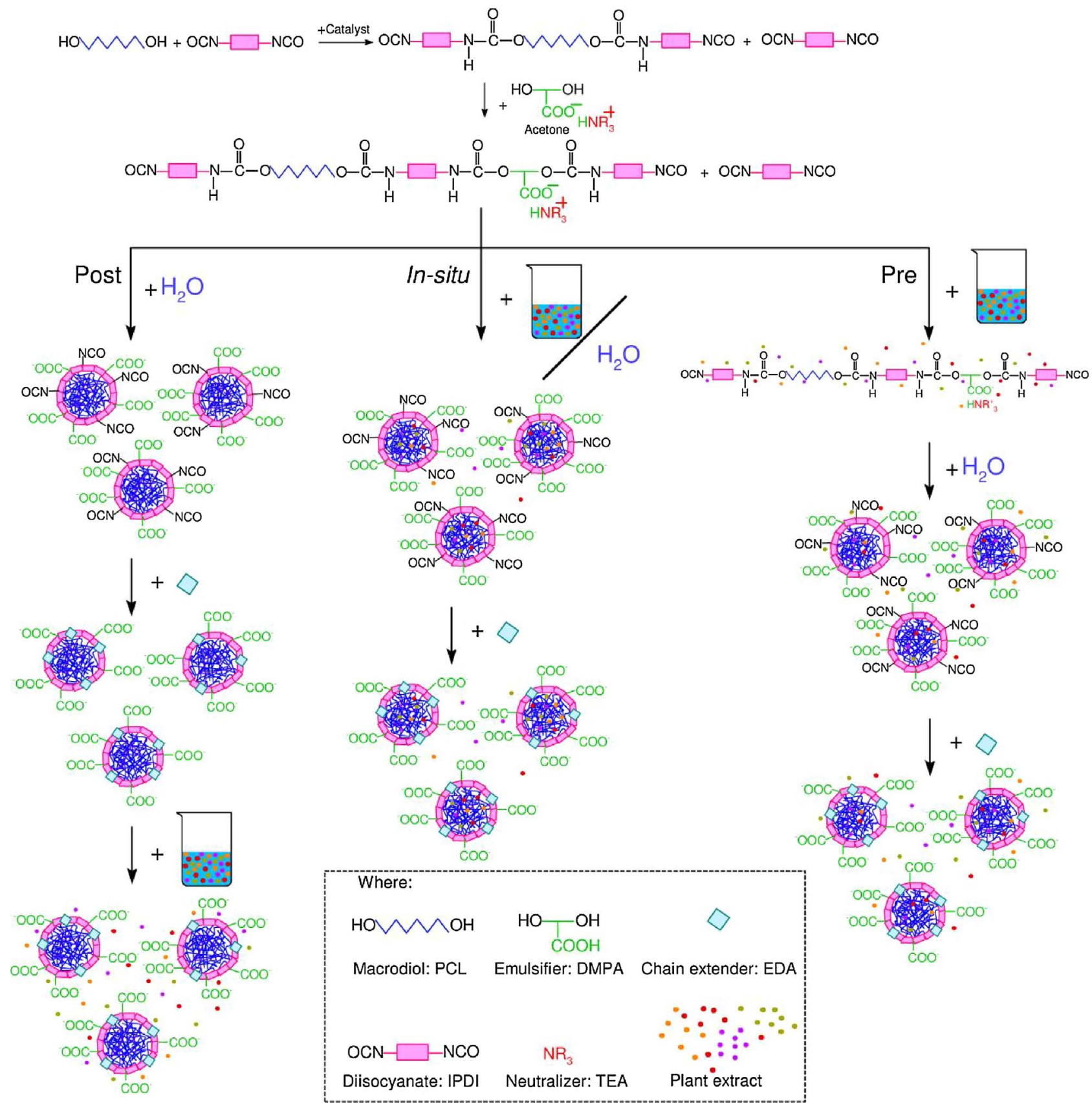

Fig. 4. Scheme of WBPUU nanoparticles intercalation mechanisms proposed considering the extracts incorporation route.

translucency in all the series. Furthermore, it is worth noting that film's color intensity varied according to the extract incorporation route, where by post method it was supposed that the extract is intercalated among polyurethane-urea nanoparticles after their formation, leading to visually more remarkable color intensity. Instead, by in-situ and pre methods, the extract could also result totally or partially embedded inside the nanoparticles due to its incorporation before or during the nanoparticles formation step. Thereby, visually lighter films were obtained comparing with their homologues prepared by the post-method.

Then, the variation in the colorimetry of the films was quantified by spectrophotometric measurements and results are shown in Table 3. With this purpose, the defined CIELAB color space $L^{*}$, $a^{*}$ and $b^{*}$ parameters were measured. $L^{*}$ axis is referred to the lightness of the sample which cover values from 0 (black) to 100 (white). In the case of $a^{*}$ and $b *$ coordinates, $a^{*}$ presents positive or negative values for red and green colors, respectively, whereas $\mathrm{b}^{*}$ positive or negative values are attributed to yellow or blue colors, respectively [36]. Furthermore, $\mathrm{L}^{*}, \mathrm{a}^{*}$ and $\mathrm{b} *$ can be employed for determining the color difference $(\Delta \mathrm{E})$ between two samples, according to the following Eq. (3) [37]:

$\Delta E=\sqrt{\left(L_{1}^{*}-L_{2}^{*}\right)^{2}+\left(a_{1}^{*}-a_{2}^{*}\right)^{2}+\left(b_{1}^{*}-b_{2}^{*}\right)^{2}}$

Analyzing L*, it was observed that base WBPUU showed the highest value attributed to the more lightness character of the film compared to samples containing extract. Regarding those bioactive films, it was appreciated that the incorporation of the extract resulted in a progressive decrease in $\mathrm{L}^{*}$ values, corroborating their darker appearance.

Furthermore, it has to be taken into account that the incorporation routes of extracts led to different intercalation mechanisms, being the trend similar for both, Salvia and Melissa plants. In the case of postmethod, where extracts were incorporated after the synthesis of the WBPUU, it was observed that even at low extract contents, the 

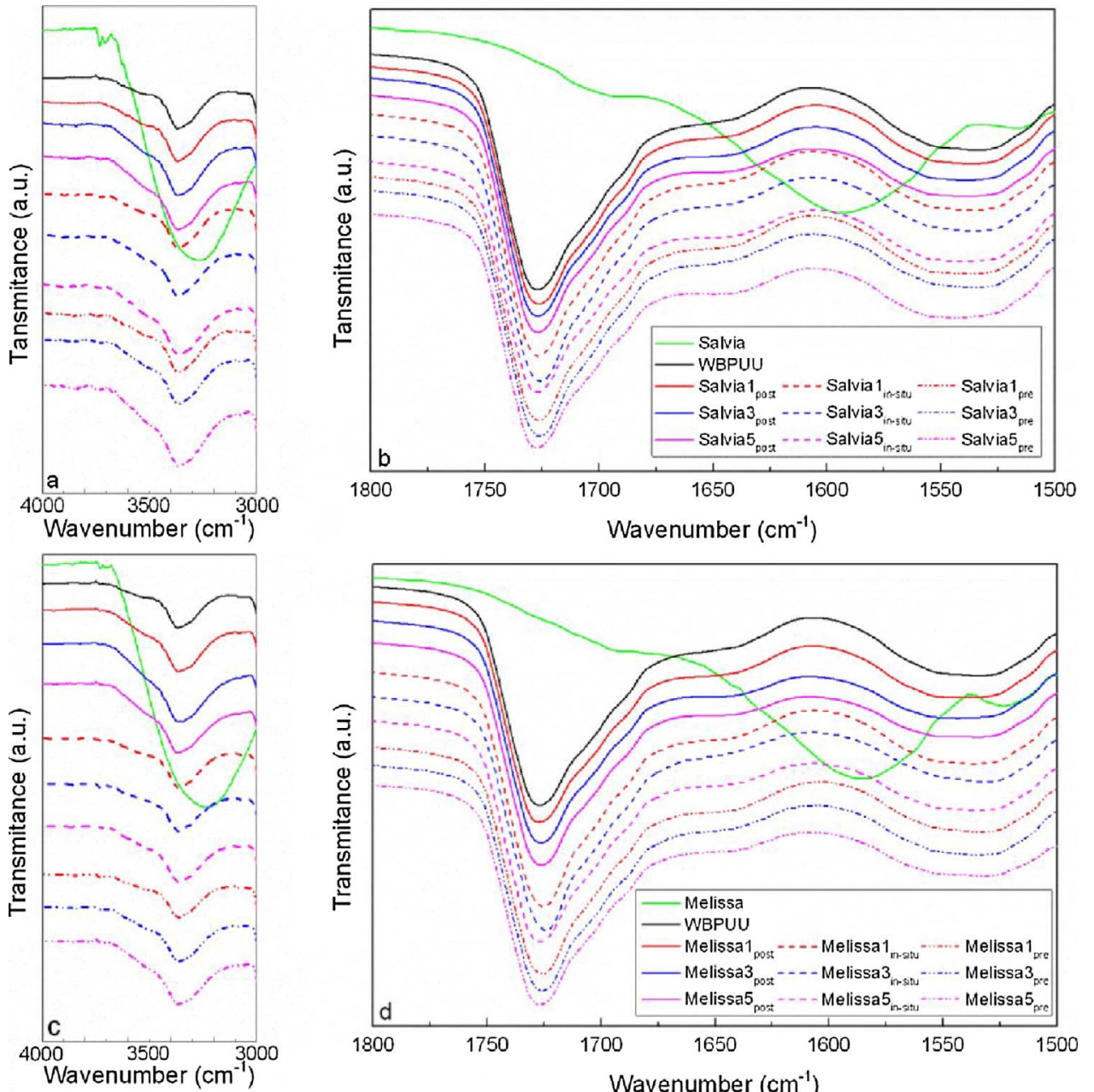

Fig. 5. FTIR spectra of base WBPUU and WBPUU containing Salvia a) in the $\mathrm{NH}$ and b) carbonyl stretching vibration regions and containing Melissa c) in the $\mathrm{NH}$ and d) carbonyl stretching vibration regions. reduction of the lightness of the films was greater than their homologues prepared by in-situ and pre-methods comparing with the base WBPUU. The slighter reduction of L* values in in-situ and pre methods, corroborated the fact of considering that the extract incorporated during the synthesis process (either before or during the particles formation), could remain embedded inside or intercalated among polyurethane-urea nanoparticles. In fact, $\Delta \mathrm{E}$ values have been determined respect to post samples for each extract content. It is known that $\Delta \mathrm{E}$ values higher than 1 indicate that the color difference is visually appreciable [38], and in this case, all films exceeded the value of 1 , meaning the existence of color difference for in-situ and pre films respect to films prepared by post-method, corroborating the influence of the incorporation route. Nevertheless, it is worth noting that high extract contents could exceed the maximum embedding capacity of the WBPUU, implying that part of the extract could only remain intercalated among polyurethane-urea nanoparticles. This fact agreed with the decrease of $\Delta \mathrm{E}$ values as extract content was increased. The proposed mechanism of extracts intercalation with the polyurethane-urea nanoparticles is shown in Fig. 4.

The functional groups, and the hydrogen bonding interactions of the base WBPUU and the Salvia- and Melissa-based WBPUU films were analyzed by FTIR (Fig. 5). Polyurethane-ureas showed two main spectral regions, namely in the ranges $3500-3100 \mathrm{~cm}^{-1}$ [39] and $1800-1600 \mathrm{~cm}^{-1}$ [40], attributed to the urethane and urea $\mathrm{N}-\mathrm{H}$ and $\mathrm{C}=\mathrm{O}$ vibrations, respectively. In the case of Salvia and Melissa extracts, a broad peak between 3700 and $3000 \mathrm{~cm}^{-1}$ was observed, related with the presence of hydroxyl groups, such as the ones of phenolic compounds [14]. Moreover, the broad band around $1700 \mathrm{~cm}^{-1}$, attributed to the $\mathrm{C}=\mathrm{O}$ of carboxylic groups, and an intense peak around $1590 \mathrm{~cm}^{-1}$ related with the $\mathrm{C}=\mathrm{C}$ of aromatic rings was also observed [41]. Thereby, only both regions of the FTIR spectra are shown in Fig. 5. Analyzing spectra in the $\mathrm{N}-\mathrm{H}$ region, Fig. 5a, only a peak can be appreciated around $3350 \mathrm{~cm}^{-1}$ for the WBPUU-based film, indicating that the $\mathrm{N}-\mathrm{H}$ of both urethane and urea groups were involved in hydrogen bonds [42]. In the case of Salvia- and Melissa-based WBPUU films, an analogous peak was observed, which increased slightly with extract content, but overlapping with their hydroxyl groups peak.

With the purpose of studying the region related with carbonyl group stretching vibration, an amplification of this region is shown in Fig. 5(b and d). In the case of the WBPUU-base film, a peak at $1726 \mathrm{~cm}^{-1}$ was detected, attributed to the $\mathrm{C}=\mathrm{O}$ groups of PCL and free $\mathrm{C}=\mathrm{O}$ groups of urethane, and a band centered at $1640 \mathrm{~cm}^{-1}$ related with the hydrogen bonded $\mathrm{C}=\mathrm{O}$ of urea groups $[43,44]$. The main peak assigned at about $1726 \mathrm{~cm}^{-1}$ was also observed in the Salvia- and Melissa-based WBPUU films. In the case of the post-method, variations were not noticeable in comparison with the base WBPUU samples. Instead, by the in-situ and pre-methods, slight differences were observed. For $3 \mathrm{wt} \%$ extract content, for both incorporation routes, the peak was shifted towards lower wavenumbers (around $1723 \mathrm{~cm}^{-1}$ ) whereas for $5 \mathrm{wt} \%$, the peak shifted slightly to higher wavenumbers (about $1728 \mathrm{~cm}^{-1}$ ), broadening also the shoulder about $1640 \mathrm{~cm}^{-1}$. The variations are barely discernible, but suggest possible changes in the interactions occurring in the films.

The thermal behavior of base WBPUU and the Salvia- and Melissabased WBPUU films was analyzed by DSC, and the obtained thermograms are shown in Fig. 6. The glass transition temperature of soft segment $\left(\mathrm{T}_{\mathrm{gSS}}\right)$, as well as the hard domain melting temperature $\left(\mathrm{T}_{\mathrm{mHS}}\right)$ 

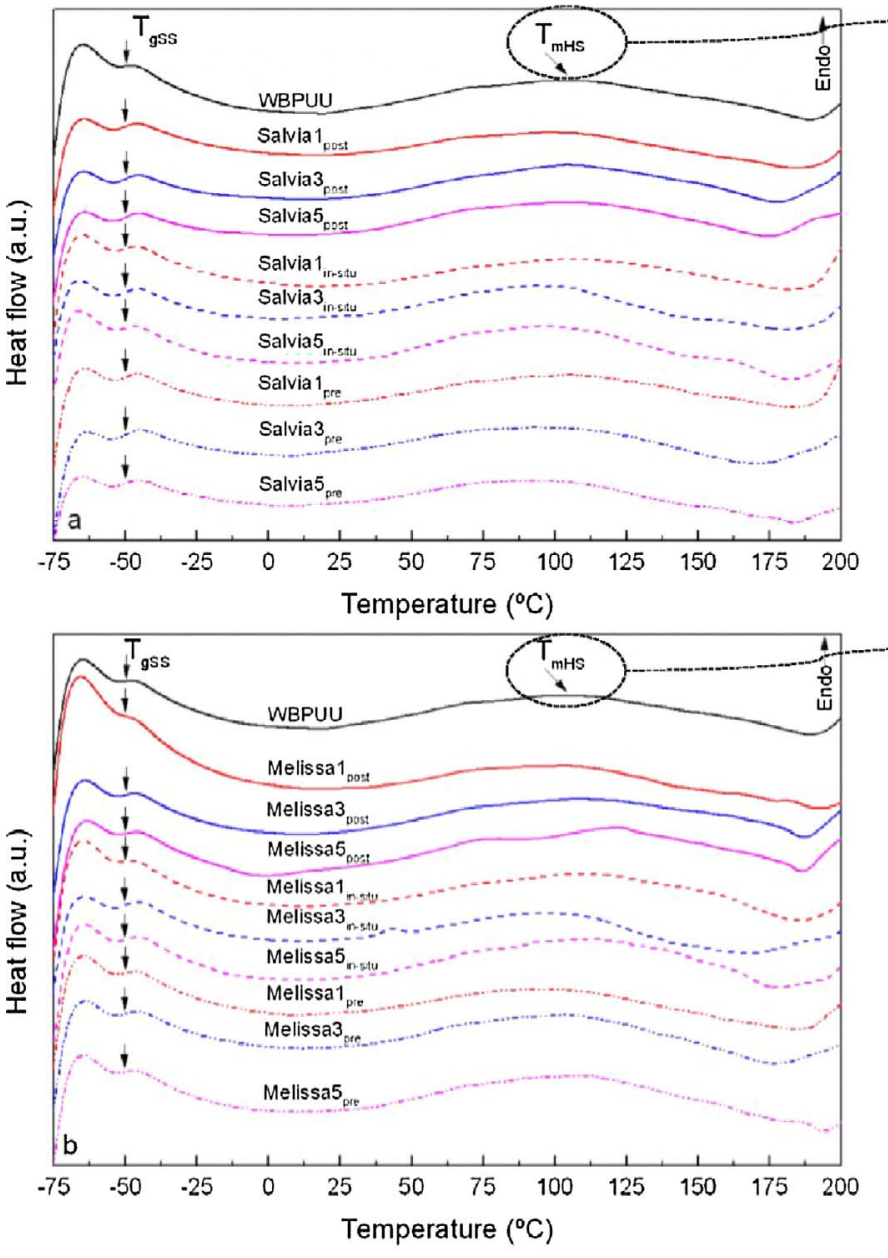

Table 4

Thermal properties of base WBPUU and WBPUU containing Salvia and Melissa extracts.

\begin{tabular}{|c|c|c|c|c|c|c|}
\hline \multirow[t]{2}{*}{ Sample } & \multicolumn{3}{|c|}{ Salvia-based WBPUU films } & \multicolumn{3}{|c|}{ Melissa-based WBPUU films } \\
\hline & $\mathrm{T}_{\mathrm{gSs}}\left({ }^{\circ} \mathrm{C}\right)$ & $\mathrm{T}_{\mathrm{mHS}}\left({ }^{\circ} \mathrm{C}\right)$ & $\begin{array}{l}\Delta \mathrm{H}_{\mathrm{mHS}} \\
\left(\mathrm{Jg}^{-1}\right)\end{array}$ & $\mathrm{T}_{\mathrm{gSs}}\left({ }^{\circ} \mathrm{C}\right)$ & $\mathrm{T}_{\mathrm{mHS}}\left({ }^{\circ} \mathrm{C}\right)$ & $\begin{array}{l}\Delta \mathrm{H}_{\mathrm{mHS}} \\
\left(\mathrm{Jg}^{-1}\right)\end{array}$ \\
\hline WBPUU & -49.8 & 99.2 & 32.1 & -49.8 & 99.2 & 32.1 \\
\hline $1_{\text {post }}$ & -50.0 & 97.4 & 23.2 & -50.0 & 102.4 & 25.5 \\
\hline $3_{\text {post }}$ & -50.0 & 103.7 & 27.7 & -50.0 & 109.2 & 35.0 \\
\hline $5_{\text {post }}$ & -50.0 & 101.8 & 27.0 & -50.0 & 122.7 & 41.3 \\
\hline $\mathbf{1}_{\text {in-situ }}$ & -50.0 & 104.9 & 22.8 & -50.0 & 105.2 & 34.7 \\
\hline $3_{\text {in-situ }}$ & -50.0 & 92.5 & 27.6 & -50.1 & 95.5 & 24.0 \\
\hline $5_{\text {in-situ }}$ & -50.0 & 93.2 & 37.2 & -50.1 & 114.2 & 37.2 \\
\hline $1_{\text {pre }}$ & -50.0 & 105.1 & 25.7 & -50.0 & 98.3 & 27.0 \\
\hline 3 pre & -50.0 & 96.1 & 27.0 & -50.1 & 104.0 & 33.0 \\
\hline $5_{\text {pre }}$ & -50.0 & 91.7 & 28.2 & -50.1 & 110.7 & 41.3 \\
\hline
\end{tabular}

and enthalpy $\left(\Delta \mathrm{H}_{\mathrm{mHS}}\right)$ for the analyzed samples are shown in Table 4.

The base WBPUU film presented a $\mathrm{T}_{\mathrm{gSs}}$ around $-50^{\circ} \mathrm{C}$, which remained similar in the extract-based films series. Furthermore, a broad transition related with the different ordering range of hard segment domains [45] was observed. In general, and comparatively with their Salvia homologues, it was observed that Melissa extract incorporation favored the ordering of hard segment domains at a greater extent, thus resulting in higher enthalpy values. In the case of the post-method, the extract content increase led to the increase of $\mathrm{T}_{\mathrm{mHS}}$ and $\Delta \mathrm{H}_{\mathrm{mHS}}$, which resulted more discernible in the case Melissa-based films. By this incorporation route, it was proposed that the extract would be intercalated between polyurethane-urea nanoparticles, which would facilitate the interactions among them, favoring the occurrence of hard
Fig. 6. DSC thermograms of base WBPUU and WBPUU containing a) Salvia and b) Melissa extracts bioactive films.

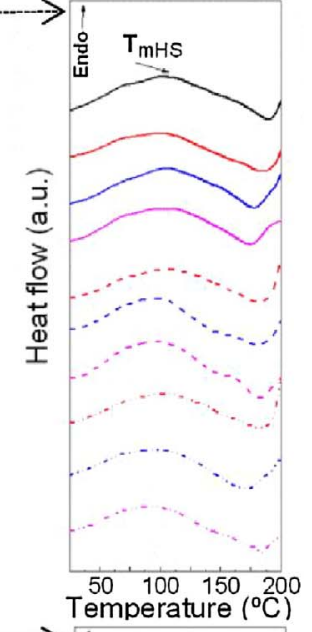

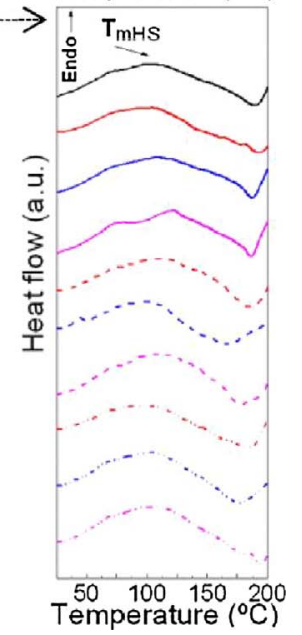

segment order domains. By contrast, by the in-situ and pre-methods, it was supposed that extract compounds could remain either inside or around the nanoparticles. In this way, in the case of Salvia extract, it was observed a decrease in $\Delta \mathrm{H}_{\mathrm{mHs}}$ at low extract content (1 wt\%). This could be promoted by the high ordered hard domains, as reflected by the significant increase in $\mathrm{T}_{\mathrm{mHs}}$ value. Then, at higher extract contents (3 and $5 \mathrm{wt} \%$ ), in general, a decrease in $\mathrm{T}_{\mathrm{mHS}}$ and an increase in $\Delta \mathrm{H}_{\mathrm{mHS}}$ were observed with Salvia-based films. This could be related with the homogeneity of extract distribution, both inside and outside the nanoparticles that interfered with higher $\mathrm{T}_{\mathrm{mHs}}$ crystals formation, but favoring interactions, leading to an increase in enthalpy. In the case of Melissa-based films, in general, the addition of extract favored the arrangement of hard order domains, resulting in a progressive increase of both, $\mathrm{T}_{\mathrm{mHS}}$ and $\Delta \mathrm{H}_{\mathrm{mHS}}$ values, except in Melissa $3_{\text {in-situ }}$ sample. It is thought that, in this case, different interactions were developed, thus resulting in such higher $\mathrm{pH}$ and viscosity values, as previously discussed.

Mechanical behavior of the Salvia- and Melissa-based WBPUU films is shown in Fig. 7. Also, for comparison, the base WBPUU film is shown. Mechanical properties obtained from stress-strain curves of base WBPU and Salvia- and Melissa-based WBPUU films are summarized in Table 5.

Comparatively with Salvia extract, it was observed that Melissa extract conferred higher stiffness to the derived films. This could be related with the previously discussed higher enthalpy values obtained by DSC. Regarding the post-method, it was observed that Salvia-based WBPUU films resulted in lower $\sigma_{\mathrm{y}}$ values than the base WBPUU film, which could be attributed to the decrease in $\Delta \mathrm{H}_{\mathrm{mHS}}$ values, as previously discussed. However, in the case of Melissa-based WBPUU films, slightly higher $\sigma_{\mathrm{y}}$ values were obtained, fact attributable to the greater 

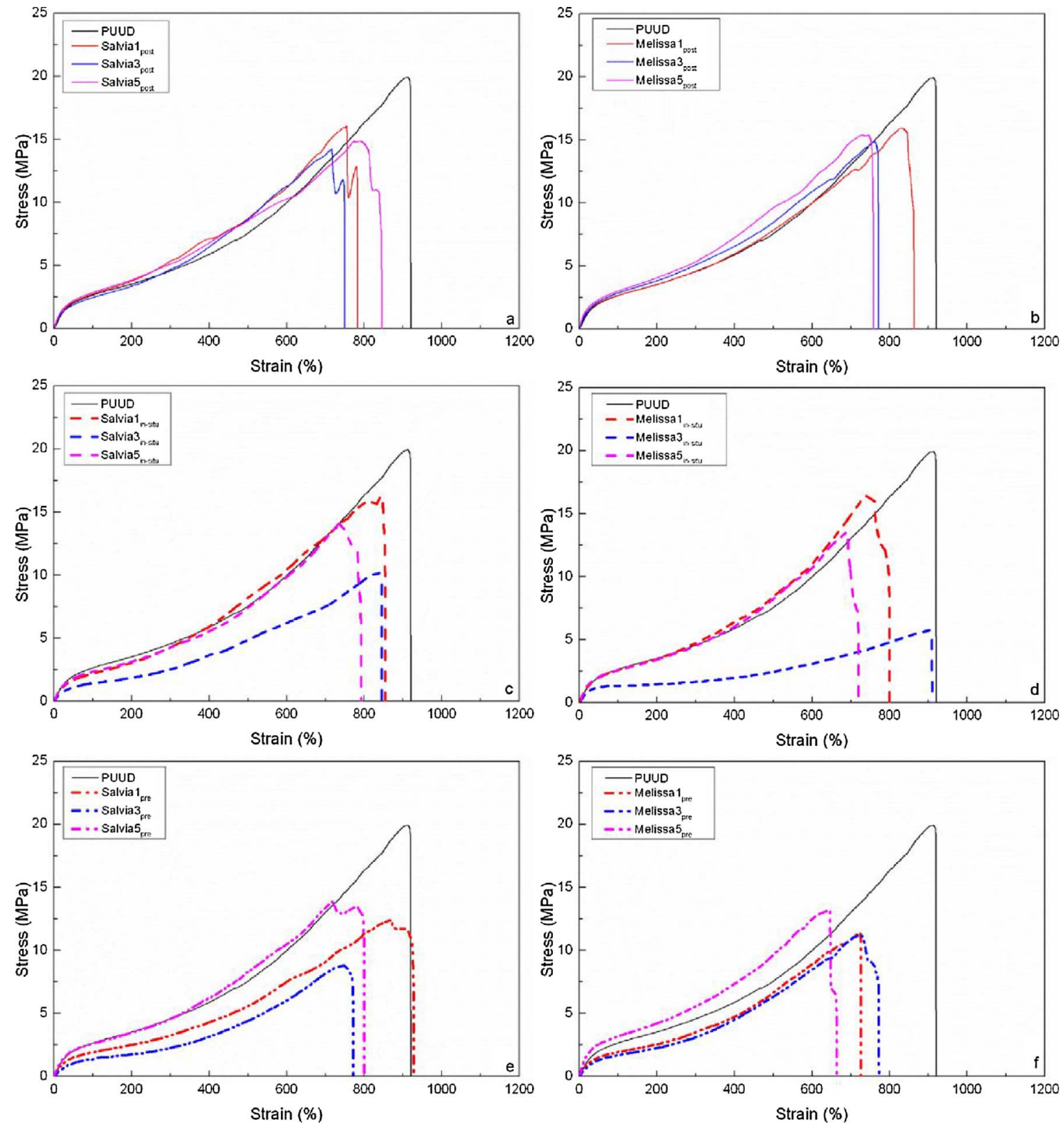

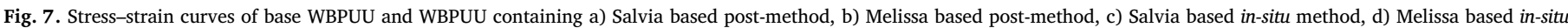
method, e) Salvia based pre-method and f) Melissa based pre-method.

Table 5

Mechanical properties of base WBPUU and WBPUU containing Salvia and Melissa extracts bioactive films.

\begin{tabular}{|c|c|c|c|c|c|c|c|c|}
\hline \multirow[t]{2}{*}{ Sample } & \multicolumn{4}{|c|}{ Salvia-based WBPUU films } & \multicolumn{4}{|c|}{ Melissa-based WBPUU films } \\
\hline & $\sigma_{\mathrm{y}}(\mathrm{MPa})$ & $\sigma_{\mathrm{b}}(\mathrm{MPa})$ & $\mathrm{E}(\mathrm{MPa})$ & $\varepsilon_{\mathrm{b}}(\%)$ & $\sigma_{\mathrm{y}}(\mathrm{MPa})$ & $\sigma_{\mathrm{b}}(\mathrm{MPa})$ & $\mathrm{E}(\mathrm{MPa})$ & $\varepsilon_{\mathrm{b}}(\%)$ \\
\hline WBPUU & $3.0 \pm 0.1$ & $18.4 \pm 1.3$ & $6.4 \pm 0.4$ & $891 \pm 51$ & $3.0 \pm 0.1$ & $18.4 \pm 1.3$ & $6.4 \pm 0.4$ & $891 \pm 51$ \\
\hline $1_{\text {post }}$ & $2.4 \pm 0.1$ & $15.9 \pm 0.3$ & $8.5 \pm 0.2$ & $738 \pm 45$ & $3.2 \pm 0.3$ & $16.4 \pm 1.9$ & $8.3 \pm 1.1$ & $848 \pm 67$ \\
\hline $3_{\text {post }}$ & $2.4 \pm 0.1$ & $14.3 \pm 1.7$ & $8.1 \pm 0.4$ & $699 \pm 52$ & $3.3 \pm 0.2$ & $15.3 \pm 3.0$ & $8.6 \pm 0.6$ & $741 \pm 70$ \\
\hline $5_{\text {post }}$ & $2.5 \pm 0.1$ & $15.0 \pm 1.0$ & $8.1 \pm 0.8$ & $777 \pm 65$ & $3.2 \pm 0.1$ & $14.9 \pm 1.1$ & $9.8 \pm 0.3$ & $740 \pm 53$ \\
\hline $\mathbf{1}_{\text {in-itu }}$ & $1.8 \pm 0.1$ & $16.4 \pm 2.2$ & $6.0 \pm 0.4$ & $878 \pm 47$ & $2.9 \pm 0.1$ & $16.0 \pm 2.0$ & $7.3 \pm 0.2$ & $766 \pm 25$ \\
\hline 3 in-itu & $1.3 \pm 0.1$ & $9.3 \pm 1.6$ & $4.5 \pm 0.2$ & $847 \pm 53$ & $1.4 \pm 0.1$ & $5.4 \pm 0.7$ & $4.8 \pm 0.2$ & $883 \pm 27$ \\
\hline 5 in-itu & $2.2 \pm 0.2$ & $13.3 \pm 0.8$ & $6.5 \pm 0.4$ & $728 \pm 30$ & $2.5 \pm 0.2$ & $14.7 \pm 1.6$ & $7.2 \pm 0.2$ & $723 \pm 27$ \\
\hline $1_{\text {pre }}$ & $1.9 \pm 0.1$ & $12.3 \pm 1.1$ & $5.5 \pm 0.3$ & $826 \pm 58$ & $2.0 \pm 0.1$ & $10.6 \pm 1.2$ & $5.0 \pm 0.2$ & $710 \pm 16$ \\
\hline $3_{\text {pre }}$ & $1.5 \pm 0.0$ & $9.3 \pm 0.7$ & $3.7 \pm 0.2$ & $796 \pm 60$ & $1.8 \pm 0.1$ & $10.9 \pm 1.3$ & $4.1 \pm 0.2$ & $769 \pm 47$ \\
\hline $5_{\text {pre }}$ & $2.6 \pm 0.0$ & $13.8 \pm 0.7$ & $7.8 \pm 0.2$ & $716 \pm 26$ & $2.9 \pm 0.2$ & $12.9 \pm 0.9$ & $10.0 \pm 0.0$ & $668 \pm 47$ \\
\hline
\end{tabular}



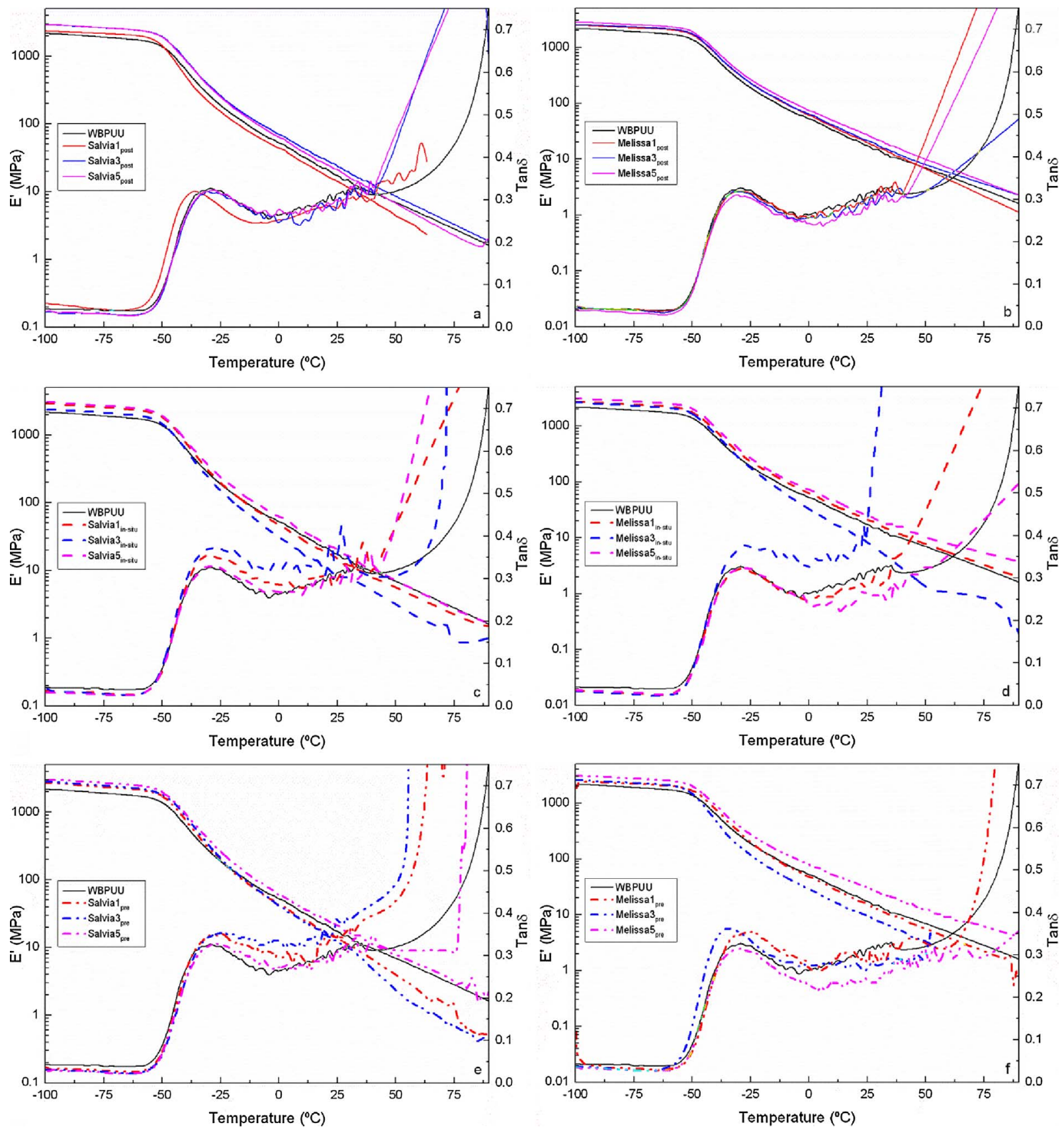

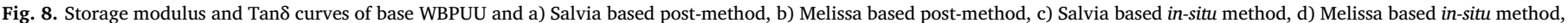
e) Salvia based pre-method and f) Melissa based pre-method.

ordering ability of hard segment domains. Nevertheless, a stiffening effect was observed for both series, which presented slightly higher $\mathrm{E}$ values together with lower $\sigma_{\mathrm{b}}$ and $\varepsilon_{\mathrm{b}}$ values. In the case of the in-situ and pre-methods, and considering the improved association of Salvia extract, both inside and outside nanoparticles, it is thought that a greater effect in the cohesion process occurred. Thus, more differences were observed comparatively with the post-method and base WBPUU samples. In this way, lower Salvia extract contents ( $1 \mathrm{wt} \%$ ) give rise to lower $\sigma_{\mathrm{y}}$ and $\mathrm{E}$ values, even lower than the ones obtained for base WBPUU films. These values increased at high extract contents (5 wt $\%$ ). In comparison, low Melissa extract contents resulted in higher $\sigma_{\mathrm{y}}$ and $\mathrm{E}$ values, which were maintained or increased for high extract contents (5\%), respectively if in-situ and pre-methods were used. These results can be related with DSC results, where enthalpy values corroborated film stiffness. It is worth noting that in the case of the use of $3 \mathrm{wt} \%$ content, in both methods, the films behavior changed. It is thought that at this extract content, a greater quantity would result embedded inside nanoparticles, conferring flexibility to the system.

The thermomechanical properties of the Salvia- and Melissa-based WBPUU films were analyzed by DMA, and E' and Tan $\delta$ curves are shown in Fig. 8. For comparison purposes, the analysis of the base WBPUU film was also included. At low temperatures, i.e. in the glassy state, it was observed for both series (Salvia- and Melissa-based), films showing E' values higher than those of base WBPUU sample. At higher temperatures, and starting from $-50{ }^{\circ} \mathrm{C}$, a decrease in E' curves, reflected as a peak in Tan $\delta$ curves, was observed, being related with the $\mathrm{T}_{\mathrm{gSs}}$ of WBPUU films. This peak temperature resulted similar for all analyzed samples, but an intensity increase was observed for samples 


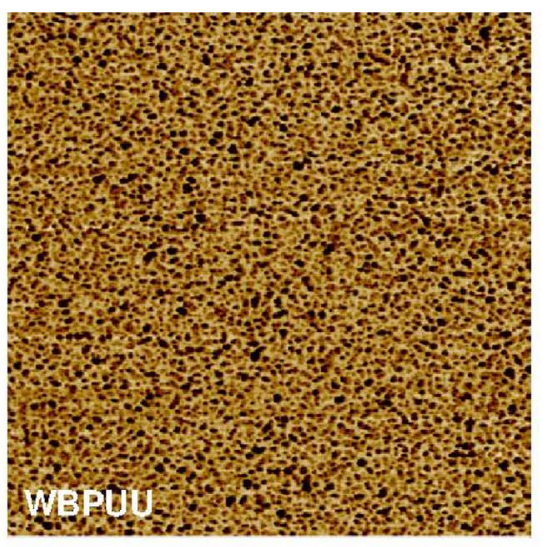

Fig. 9. AFM phase images of base WBPUU and WBPUU containing $3 \mathrm{wt}$ $\%$ of Salvia and Melissa extract (size: $3 \times 3 \mu^{2}$ ).
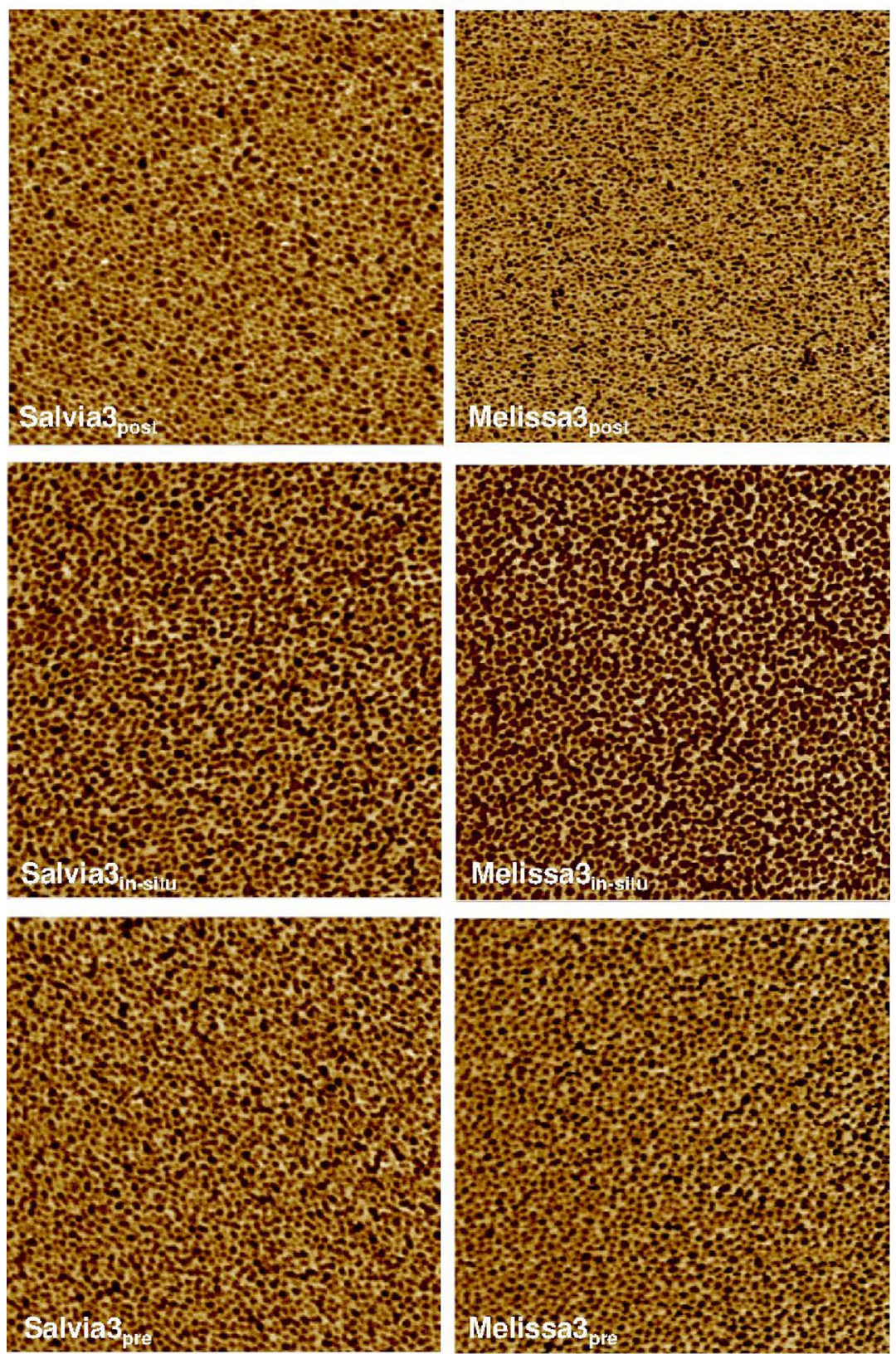

prepared by the in-situ and pre-methods with extract contents of 1 and $3 \mathrm{wt} \%$. This fact can be attributed to the greater amount of polyurethane-urea chains involved in the transition [46]. As the temperature increased, i.e. as the polyurethane-urea chains acquired mobility, and for samples prepared by the post-method, E' curves remained above the one of the base WBPUU sample, probably due to the stiffening effect already depicted in the mechanical properties results. An exception was observed with the sample Salvia $1_{\text {post }}$, where, previously to flow, the 


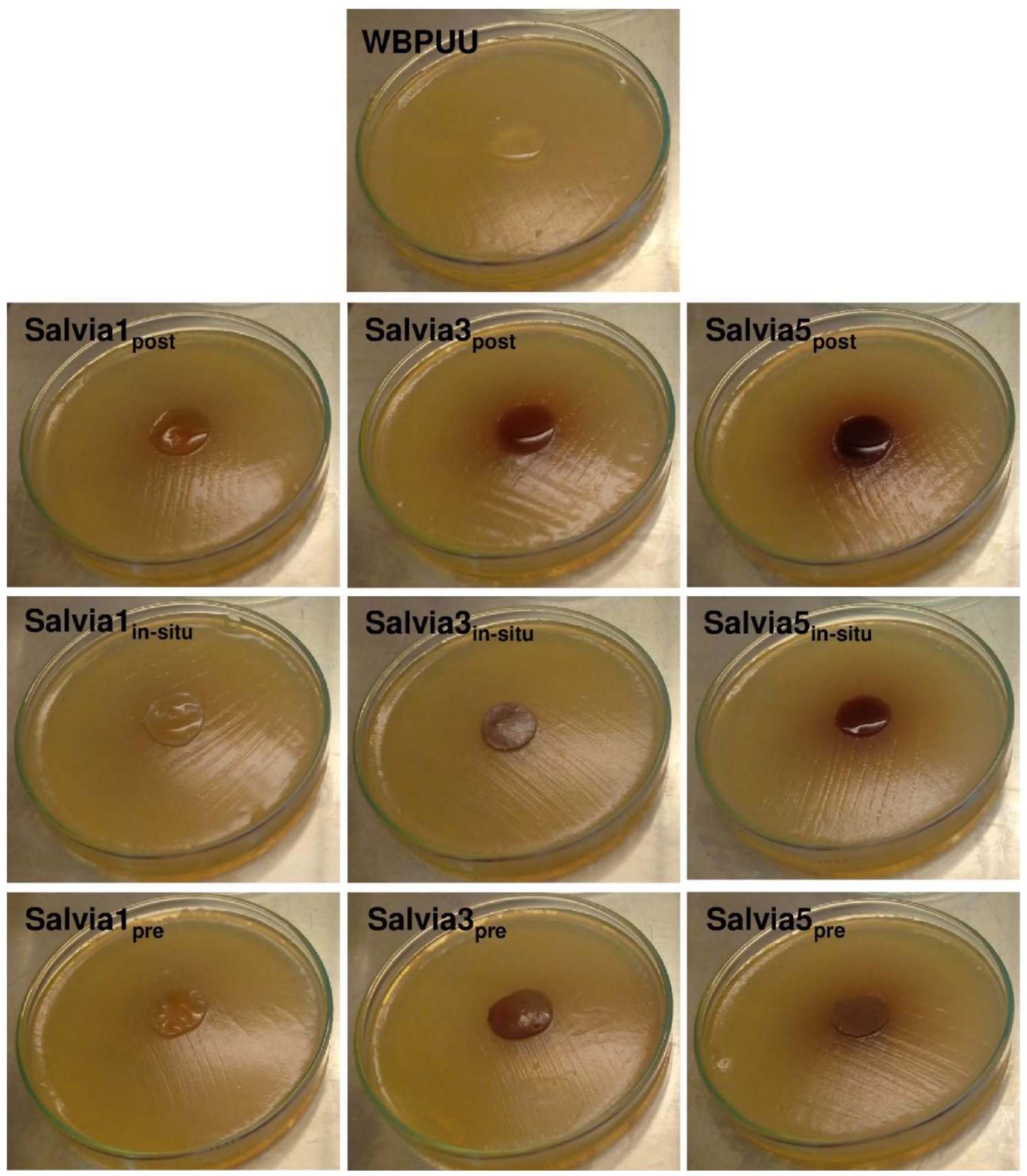

Fig. 10. Antibacterial tests of base WBPUU and WBPUU containing Salvia extract against E. coli after 4 days of incubation at $37^{\circ} \mathrm{C}$.

produced film showed a lower E' value. Instead, in the case of the in-situ and pre-methods, once temperature exceeds $\mathrm{T}_{\mathrm{gss}}$, only the film containing $5 \mathrm{wt} \%$ of Salvia extract was able to maintain a E' value higher than those of the base WBPUU film. In the case of Melissa-based WBPUU films, E' curves showed higher values than those of base WBPUU films, with the exception of the ones containing $3 \mathrm{wt} \%$ extract. This fact would be attributed to the lower stiffness of those films, as discussed previously in the mechanical properties section.

The morphology of the base WBPUU and Salvia- and Melissa-based WBPUU films, containing $3 \mathrm{wt} \%$ of extract, was analyzed by AFM. Phase images of Salvia and Melissa series are shown in Fig. 9. Analyzing the AFM images, it was observed that the base WBPUU films showed bright and dark regions attributed to the hard and soft domains reflecting the microphase morphology of the polyurethane-urea [47]. For the WBPUU samples containing an extract content of $3 \mathrm{wt} \%$, although it was not possible to discern the presence of extract, some variations were observed in the morphology of the base polyurethane-urea material. The spherical morphology observed in the base WBPUU film was also observed in the films incorporating the extracts; nevertheless, a more defined spherical microstructure was notice in these samples. This fact can be attributed to polyurethane-urea nanoparticles constituting the dispersion, suggesting a suitable cohesiveness during film formation. It is worth noting that in the case of the in-situ method, for both extracts, the morphology was the more discernible among the used methods, and in the case of Melissa-based films, it seemed even to be appreciated the connectivity among some nanoparticles. The analyzed microstructures would support the idea that the extract could act as a surfactant facilitating the formation of the polyurethane-urea nanoparticles.

The antimicrobial properties of the Salvia- and Melissa-based 
Table 6

Antibacterial properties of base WBPUU and WBPUU containing Salvia extracts.

\begin{tabular}{|c|c|c|c|c|c|c|}
\hline \multirow[t]{2}{*}{ Sample } & \multicolumn{3}{|l|}{1 day } & \multicolumn{3}{|l|}{4 days } \\
\hline & S. aureus & E. coli & P. aeruginosa & S. aureus & E. coli & P. aeruginosa \\
\hline \multicolumn{7}{|l|}{ WBPUU } \\
\hline \multicolumn{7}{|l|}{ Salvia $1_{\text {post }}$} \\
\hline \multicolumn{7}{|l|}{ Salvia $_{\text {post }}$} \\
\hline \multicolumn{7}{|l|}{ Salvia5 $_{\text {post }}$} \\
\hline \multicolumn{7}{|c|}{ Salvia $_{\text {in-situ }}$} \\
\hline \multicolumn{7}{|c|}{ Salvia3 ${ }_{\text {in-situ }}$} \\
\hline \multicolumn{7}{|c|}{ Salvia5 $_{\text {in-situ }}$} \\
\hline \multicolumn{7}{|l|}{ Salvia $_{\text {pre }}$} \\
\hline \multicolumn{7}{|l|}{ Salvia $3_{\text {pre }}$} \\
\hline Salvia5 $_{\text {pre }}$ & & & & & & \\
\hline
\end{tabular}

There was not bacteria growth on the surface or behind the film.

c) There was bacteria growth on the surface or behind the film.

Table 7

Antibacterial properties of base WBPUU and WBPUU containing Melissa extracts.

\begin{tabular}{|c|c|c|c|c|c|c|}
\hline \multirow[t]{2}{*}{ Sample } & \multicolumn{3}{|l|}{1 day } & \multicolumn{3}{|l|}{4 days } \\
\hline & S. aureus & E. coli & P. aeruginosa & S. aureus & E. coli & P. aeruginosa \\
\hline WBPUU & & & & & as & 6 \\
\hline Melissa $_{\text {pos }}$ & & & & & & \\
\hline Melissa $_{\text {pos }}$ & & & & & & \\
\hline Melissa5 $_{\text {pos }}$ & & & & & & \\
\hline Melissa $_{\text {in-s }}$ & & & & & & \\
\hline Melissa $_{\text {in-s }}$ & & & & & & \\
\hline Melissa $_{\text {in-s }}$ & & & & & & \\
\hline Melissa $_{\text {pre }}$ & & & & & & \\
\hline Melissa $_{\text {pre }}$ & & & & & & \\
\hline Melissa5 $_{\text {pre }}$ & & & & & & \\
\hline
\end{tabular}

There was not bacteria growth on the surface or behind the film.

as There was bacteria growth on the surface or behind the film.

WBPUU films were analyzed against Gram positive bacteria Staphylococcus aureus ATCC 19213 and Gram negative Escherichia coli ATCC 10536 and Pseudomonas aeruginosa ATCC 9027 as test microorganisms and analyzed at 1 and 4 days of incubation at $37^{\circ} \mathrm{C}$. Fig. 10 shows images of Salvia based films incubated after 4 days against $E$. coli. Considering the extract incorporation route, it can be observed that films prepared by post-method presented a brown halo surrounding the films, consisting on the lixiviated extract, which resulted more discernible as the extract content was increased. However, in samples prepared by in-situ and pre-methods, the absence of the halo indicated the embedding effect of the extract by polyurethane-urea nanoparticles, except for samples containing $5 \mathrm{wt} \%$ of extract. In this case, taking into account that the maximum embedding capacity was exceeded, the rest of the extract remained just intercalated among polyurethane-urea nanoparticles, and thus lixiviated to the medium as can be observed in Fig. 10. These results agreed with colorimetry tests of the films, where lower $\Delta \mathrm{E}$ values were observed at high extract content due to the existence of extract fraction not embedded into the polyurethane-urea nanoparticles.

Regarding antibacterial properties, results achieved after 1 and 4 days, at an incubation temperature of $37^{\circ} \mathrm{C}$, are summarized in Tables 6 and 7, respectively for Salvia- and Melissa-based films. It was observed that after an incubation period of 1 day, Salvia- and Melissabased WBPUU films, presented bacteriostatic effect against bacteria, hindering their growth along the film. It was also the case of the base WBPUU film. After an incubation period of 4 days the inhibitory power of the base WBPUU sample ceased for all the assayed bacteria, whereas the WBPUU films added with extracts showed a distinct behaviors with a pattern dependent of the used incorporation route. Regarding Gram positive $S$. aureus, it was observed that the inhibitory effect caused by the incorporation of Salvia extract was only effective in the case where the in-situ method was used, and at extract contents of 3 and $5 \mathrm{wt} \%$, whereas in the case of Melissa extract the bacteriostatic effect was maintained in all the series. The aqueous extracts, obtained from 
Melissa, are known for presenting antibacterial activity against this bacterium [48]. Thereby, in this case, this extract resulted effective embedded in the polyurethane-urea nanoparticles (in-situ method) where the extract activity is protected and favored [49], as well as free among nanoparticles in the film (post-method). Instead, this effect was not observed in the case of Salvia extracts, were the higher $\mathrm{pH}$ values can contribute to the poorer bacteriostatic effect [50]. In general, in the case of Salvia, the aqueous extract did not result in a significant effect against $S$. aureus. Only if the in-situ method was used the bacteriostatic character of films remained after 4 incubation days. In the case of $E$. coli, other tendencies were observed. For Salvia extract, the bacteria growth was inhibited in most of the derived films indicating its effectiveness against this bacterium. Exceptions were found for films containing $1 \mathrm{wt} \%$ incorporated by the in-situ and pre-methods. In these cases, considering the low content of extract, and the fact that it could have remained totally embedded, the inhibition effect was hindered. The same tendency was observed against $P$. aeruginosa. Furthermore, taking into account that $P$. aeruginosa is more resistant, if compared with $E$. coli (being both Gram negative bacteria), the incorporation through the post-method did not result effective, probably due the lixiviation effects along time. Regarding Melissa extract, the bacteriostatic effect against $E$. coli was maintained in all the series, except when 1 and $3 \mathrm{wt} \%$ of extract was incorporated through the pre-method. However, at low extract content $(1 \mathrm{wt} \%)$ the bacteriostatic effect against $P$. aeruginosa was not effective; at higher contents, and using the post- and in-situ methods, the inhibition effect was achieved after 4 days of incubation, whereas in the case of the pre-method, it was not possible even at high extract contents.

\section{Conclusions}

In this work polyurethane-urea dispersions were synthesized, with and without added extracts from Salvia officinalis L. and Melissa officinalis L., aiming at examining the effect of the used incorporation route and extract content on the observed physicochemical, thermo, mechanical, thermomechanical and antimicrobial properties. In this way, extracts at contents of 1,3 and $5 \mathrm{wt} \%$ were incorporated into the polyurethane-urea dispersions by using three different incorporation routes: post-method, in-situ method and pre-method.

In a general way, it was observed that the extract content, as well as the incorporation route, influenced the final properties of the prepared films. Among them, it was observed that the WBPUU dispersions become more viscous as the extract content increases. Also, the fact that WBPUU particle size distributions broaden to lower sizes with the adding of extracts, put in evidence their surfactant effect. Regarding thermal properties, and compared with the Salvia homologues, Melissa extract favored, at a greater extent, the ordering ability of hard domains, being this effect more noticeable when samples are prepared by the post-method. Considering that extracts could result embedded inside the WBPUU particles, when both the in-situ and pre-methods are applied, $\Delta \mathrm{H}_{\mathrm{mHs}}$ increase was hindered in some samples. This fact impacts on the achieved mechanical properties, where a stiffening effect was observed when the post-method was used. The use of both in-situ and the pre-methods, and extract incorporation at a content of $3 \mathrm{wt} \%$, render films more flexible, fact related with the extract distribution within the polyurethane-urea nanoparticles. In this way, these samples showed lower E' values when compared with the base WBPUU film. The morphology of WBPUU samples containing extract at a content of $3 \mathrm{wt}$ $\%$, as analyzed by AFM, revealed that the spherical morphology observed for the base WBPUU sample, resulted more discernible in the presence of extract, corroborating their surfactant effect. Antibacterial tests revealed that after 1 day of incubation, all samples (base WBPUU and Salvia- and Melissa-based WBPUU series), showed bacteriostatic effect against the analyzed $S$. aureus, E. coli and P. aeruginosa bacteria. After 4 days of incubation, only some samples containing Salvia or Melissa extract, presented bacteriostatic effect, being the magnitude of the effect dependent of the used extract content and incorporation route. This effect can be attributed, either to the extracts itself or to their distribution in the WBPUU system.

\section{Acknowledgments}

Financial support from the Basque Government (IT-776-13), the Spanish Ministry of Economy and Competitiveness (MINECO) (MAT2016-76294-R), POCI-01-0145-FEDER-006984 (LA LSRE-LCM) funded by ERDF through POCI-COMPETE2020 and FCT and NORTE01-0145-FEDER-000006, funded by NORTE 2020, under PT2020 through ERDF is gratefully acknowledged. We also wish to acknowledge the "Macrobehaviour- Mesostructure-Nanotechnology" SGIker units from the University of the Basque Country, for their technical support. A.S-E thanks the University of the Basque Country for Ph.D. grant (PIF/UPV/12/201).

\section{References}

[1] Y.S. Hu, Y. Tao, C.P. Hu, Polyurethaneurea/vinyl polymer hybrid aqueous dispersions based on renewable material, Biomacromolecules 2 (2001) 80-84.

[2] Y. Li, B.A.J. Noordover, R.A.T.M. Van Benthem, C.E. Koning, Bio-based poly(urethane urea) dispersions with low internal stabilizing agent contents and tunable thermal properties, Prog. Org. Coat. 86 (2015) 134-142.

[3] V. García-Pacios, V. Costa, M. Colera, J. Miguel Martín-Martínez, Affect of polydispersity on the properties of waterborne polyurethane dispersions based on polycarbonate polyol, Int. J. Adhes. Adhes. 30 (2010) 456-465.

[4] Y. Li, B.A.J. Noordover, R.A.T.M. Van Benthem, C.E. Koning, Property profile of poly(urethane urea) dispersions containing dimer fatty acid-, sugar- and amino acid-based building blocks, Eur. Polym. J. 59 (2014) 8-18.

[5] M. Villani, J. Scheerder, R.A.T.M. Van Benthem, G. De With, Interfacial interactions of poly(urethane-urea) based primers with polypropylene, Eur. Polym. J. 56 (2014) $118-130$.

[6] L. Lei, L. Zhong, X. Lin, Y. Li, Z. Xia, Synthesis and characterization of waterborne polyurethane dispersions with different chain extenders for potential application in waterborne ink, Chem. Eng. J. 253 (2014) 518-525.

[7] Y.S. Kwak, E.Y. Kim, B.H. Yoo, H. Do Kim, Preparation and properties of waterborne poly(urethane urea)s for adhesives: the effects of the 2, 2-bis(hydroxylmethyl) propionic acid content on the properties, J. Appl. Polym. Sci. 94 (2004).

[8] Q.B. Meng, S. Il Lee, C. Nah, Y.S. Lee, Preparation of waterborne polyurethanes using an amphiphilic diol for breathable waterproof textile coatings, Prog. Org. Coat. 66 (2009) 382-386.

[9] M.R. Chashmejahanbin, H. Daemi, M. Barikani, A. Salimi, Noteworthy impacts of polyurethane-urea ionomers as the efficient polar coatings on adhesion strength of plasma treated polypropylene, Appl. Surf. Sci. 317 (2014) 688-695.

[10] Z. Wang, Z. Hou, Y. Wang, Fluorinated waterborne shape memory polyurethane urea for potential medical implant application, J. Appl. Polym. Sci. 127 (2013) $710-716$.

[11] O. Stefanović, L. Comic, Synergistic antibacterial interaction between Melissa of ficinalis extracts and antibiotics, J. Appl. Pharm. Sci. 2 (2012) 1-5.

[12] B. Pawlikowska-Pawlęga, L.E. Misiak, B. Zarzyka, R. Paduch, A. Gawron, W.I. Gruszecki, FTIR, 1H NMR and EPR spectroscopy studies on the interaction of flavone apigenin with dipalmitoylphosphatidylcholine liposomes, Biochim. Biophys. Acta 1828 (2013) 518-527.

[13] R. Venkataswamy, A. Doss, H.M. Mubarack, M. Sukumar, Phytochemical, HPTLC finger printing and antibacterial activity of Acacia nilotica (L.) Delile, Hygeia J. Drugs Med. 2 (2010) 38-42.

[14] N. Martins, L. Barros, C. Santos-Buelga, M. Henriques, S. Silva, I.C.F.R. Ferreira, Evaluation of bioactive properties and phenolic compounds in different extracts prepared from Salvia officinalis L, Food Chem. 170 (2015) 378-385.

[15] M. Ghorbanpour, M. Hatami, K. Kariman, P. Abbaszadeh Dahaji, Phytochemical variations and enhanced efficiency of antioxidant and antimicrobial ingredients in Salvia officinalis as inoculated with different rhizobacteria, Chem. Biodivers. 13 (2016) 319-330.

[16] B. Pavli, N. Teslic, A. Vidakovi, S. Vidovic, A. Velicanski, A. Versari, R. Radosavljević, Z. Zeković, Sage processing from by-product to high quality powder: I. Bioactive potential, Ind. Crop Prod. 107 (2017) 81-89.

[17] A.R. Jassbi, S. Zare, O. Firuzi, J. Xiao, Bioactive phytochemicals from shoots and roots of Salvia species, Phytochem. Rev. 15 (2016) 829-867.

[18] B. Pavlić, S. Vidović, J. Vladić, R. Radosavljević, M. Cindrić, Z. Zeković, Subcritical water extraction of sage (Salvia officinalis L.) by-products-Process optimization by response surface methodology, J. Supercrit. Fluids 116 (2016) 36-45.

[19] E.L. Bakota, J.K. Winkler-Moser, Ma.A. Berhow, F.J. Eller, S.F. Vaughn, Antioxidant activity and sensory evaluation of a rosmarinic acid-enriched extract of salvia officinalis, J. Food Sci. 80 (2015) 711-717.

[20] M. Carocho, L. Barros, R.C. Calhelha, A. Ćirić, M. Soković, C. Santos-Buelga, et al., Melissa officinalis L. decoctions as functional beverages: a bioactive approach and chemical characterization, Food Funct. 6 (2015) 2240-2248.

[21] K. Dastmalchi, H.J.D. Dorman, P.P. Oinonen, Y. Darwis, I. Laakso, R. Hiltunen, Chemical composition and in vitro antioxidative activity of a lemon balm (Melissa 
officinalis L.) extract, LWT 41 (2008) 391-400.

[22] O.G. Echem, V.I. Chukwuike, Corrosion inhibition efficiency of lemon balm (Melissa officinalis) leaves extract on aluminium in $1 \mathrm{M} \mathrm{HCl}$ at different temperatures, Am. J. Chem. Appl. 2 (2015) 27-31.

[23] S. Miraj, N. Azizi, S. Kiani, A review of chemical components and pharmacological effects of Melissa officinalis L, Der Pharm. Lett. 8 (2016) 229-237.

[24] A. Tashakor, M.R. Kelishadi, A. Ghasemi, F. Daylami, A. Rahimi, S.Z. Doabi, N.N. Abdolusefi, Effects of hydroalcoholic extract in Mellissa officinalis plant on fat profiles and glucose level in diabetic rats induced by streptozotocin, J. Chem. Pharm. Res. 8 (2016) 402-406.

[25] F. Cunha, S.R. Tintino, F. Figueredo, L. Barros, A.E. Duarte, Ma.C. Vega Gomez, C.C. Coronel, M. Rolón, N. Leite, C.E. Sobral-Souza, S.V. Brito, E.P. Waczuc, A.A. Boligon, M. Athayde, J.P. Kamdem, H.D. Melo Coutinho, J. Franco, HPLC-DAD phenolic profile, cytotoxic and anti-kinetoplastidae activity of Melissa officinalis, Pharm. Biol. 9 (2016) 1664-1670.

[26] Y. Gerasymchuk, A. Lukowiak, A. Wedzynska, A. Kedziora, G. Bugla-Ploskonska, D. Piatek, T. Bachanek, V. Chernii, L. Tomachynski, W. Strek, New photosensitive nanometric graphite oxide composites as antimicrobial material with prolonged action, J. Inorg. Biochem. 159 (2016) 142-148.

[27] A. Piozzi, I. Francolini, L. Occhiaperti, M. Venditti, W. Marconi, Antimicrobial activity of polyurethanes coated with antibiotics: a new approach to the realization of medical devices exempt from microbial colonization, Int. J. Pharm. 280 (2004) 173-183.

[28] V.D. Athawale, M.A. Kulkarni, Effect of dicarboxylic acids on the performance properties of polyurethane dispersions, J. Appl. Polym. 117 (2010) 572-580.

[29] V. García-Pacios, Y. Iwata, M. Colera, J.M. Miguel Martín-Martínez, Influence of the solids content on the properties of waterborne polyurethane dispersions obtained with polycarbonate of hexanediol, Int. J. Adhes. Adhes. 31 (2011) 787-794.

[30] C.H. Tsou, H.T. Lee, W.S. Hung, M. De Guzman, S.T. Chen, M.C. Suen, S.T. Wicaksono, Effects of different metals on the synthesis and properties of waterborne polyurethane composites containing pyridyl units, Polym. Bull. 74 (2017) $1121-1143$

[31] T. Sharma, G.S. Kumar, B.H. Chon, J.S. Sangwai, Viscosity of the oil-in-water pickering emulsion stabilized by surfactant-polymer and nanoparticle-surfactantpolymer system, Korea-Aust. Rheol. J. 26 (2014) 377-387.

[32] A.K. Nanda, D.A. Wicks, S.A. Madbouly, J.U. Otaigbe, Effect of ionic content solid content, degree of neutralization, and chain extension on aqueous polyurethane dispersions prepared by prepolymer method, J. Appl. Polym. Sci. 98 (2005) 2514-2520.

[33] L. Tmáková, S. Sekretár, Š. Schmidt, Plant-derived surfactants as an alternative to synthetic surfactants: surface and antioxidant activities, Chem. Pap. 70 (2016) $188-196$.

[34] K. Holmberg, Natural surfactants, Curr. Opin. Colloid Interface Sci. 6 (2001) 148-159.

[35] S. Salati, G. Papa, F. Adani, Perspective on the use of humic acids from biomass as natural surfactants for industrial applications, Biotechnol. Adv. 29 (2011) 913-922.
[36] A. Terrab, L. Gonzalez-Miret, F.J. Heredia, Colour characterisation of thyme and avocado honeys by diffuse reflectance spectrophotometry and spectroradiometry, Eur. Food Res. Technol. 218 (2004) 488-492.

[37] M. García-Marino, M.L. Escudero-Gilete, F.J. Heredia, M.T. Escribano-Bailón, J.C. Rivas-Gonzalo, Color-copigmentation stuudy by tristimulus colorimetry (CIELAB) in red wines obtained from Tempranillo and Graciano varieties, Food Res. Int. 51 (2013) 123-131.

[38] M. Gil, F. Avila-Salas, L.S. Santos, N. Iturmendi, V. Moine, V. Cheynier, C. Saucier, Rose wine fining using polyvinylpolypyrrolidone: colorimetry, targeted polyphenomics and molecular dynamics simiulations, J. Agric. Food Chem. 65 (2017) 10591-10597, http://dx.doi.org/10.1021/acs.jafc.7b04461.

[39] A.K. Mishra, D.K. Chattopadhyay, B. Sreedhar, K.V.S.N. Raju, XFT-IR and XPS studies of polyurethane-urea-imide coatings, Prog. Org. Coat. 55 (2006) 231-243.

[40] Y. Shi, X. Zhan, Z. Luo, Q. Zhang, F. Chen, Quantitative IR characterization of urea groups in waterborne polyurethanes, J. Polym. Sci. Part A Polym. Chem. 46 (2008) 2433-2444.

[41] Z. Rafiee, M. Barzegar, M.A. Sahari, B. Maherani, Nanoliposomal carriers for improvement the bioavailability of high - valued phenolic compounds of pistachio green hull extract, Food Chem. 220 (2017) 115-122.

[42] I. Yilgör, E. Yilgör, G.L. Wilkes, Critical parameters in designing segmented polyurethanes and their effect on morphology and properties: a comprehensive review, Polymer (Guildf). 58 (2015) A1-A36.

[43] M.A. Pérez-Limiñana, F. Arán-Aís, A.M. Torró-Palau, C. Orgilés-Barcel, J.M. MartínMartínez, Influence of the hard-to-soft segment ratio on the adhesion of waterborne polyurethane adhesive, J. Adhes. Sci. Technol. 21 (2007) 755-773.

[44] J.T. Garrett, R. Xu, J. Cho, J. Runt, Phase separation of diamine chain-extended poly(urethane) copolymers: FTIR spectroscopy and phase transitions, Polymer 44 (2003) 2711-2719.

[45] C. Fang, X. Zhou, Q. Yu, S. Liu, D. Guo, R. Yu, J. Hu, Synthesis and characterization of low crystalline waterborne polyurethane for potential application in water-based ink binder, Prog. Org. Coat. 77 (2014) 61-71.

[46] M.L. Auad, V.S. Contos, S. Nutt, M.I. Aranguren, N.E. Marcovich, Characterization of nanocellulose-reinforced shape memory polyurethanes, Polym. Int. 57 (2008) 651-659.

[47] S. Das, P. Pandey, S. Mohanty, S.K. Nayak, Influence of NCO-OH and trans esterified castor oil on the structure and properties of polyurethane: synthesis and characterization, Mater. Express 5 (2015) 377-389.

[48] O. Stefanovic, I. Radojevic, S. Vasic, L. Comic, Antimicrobial agents in: Antibacterial activity of naturally occurring compounds from selected plants, InTech, Croatia, 2012, pp. 1-24.

[49] R. Moghimi, A. Aliahmadi, D.J. McClements, H. Rafati, Investigations of the effectiveness of nanoemulsions from sage oil as antibacterial agents on some food borne pathogens, LWT - Food Sci. Technol. 71 (2016) 69-76.

[50] M. Hosseinnejad, S. Mahdi, Evaluation of different factors affecting antimicrobial properties of chitosan, Int. J. Biol. Macromol. 85 (2016) 467-475. 